\title{
Fabrication, Structure and Properties of Nanostructured Ceramic Membranes
}

\author{
Ian W. M. Brown ${ }^{1,2}$, Jeremy P. Wu ${ }^{2}$ and Geoff Smith ${ }^{2}$ \\ ${ }^{1}$ The MacDiarmid Institute for Advanced Materials and Nanotechnology \\ 2Industrial Research Ltd (IRL), Lower Hutt \\ New Zealand
}

\section{Introduction}

The fabrication of nanostructured ceramic membranes by anodising pure aluminium in various acidic electrolytes has attracted considerable attention in recent years because the anodisation process enables the preparation of films with well controlled, uniform pores from tens to several hundreds of nanometres in diameter. The basic cell structure containing cylindrical pores has long been known (O'Sullivan \& Wood, 1970; Furneaux et al., 1989) and methods for preparing pore arrays in a hexagonal pattern with interpore distances of between 50 to $500 \mathrm{~nm}$ have been reported (Masuda \& Fukuda, 1995; Masuda et al., 1997, 1998; Li et al., 1998). The preparation of regular pore arrays typically involves electrolytic polishing and multiple anodising steps or even mechanical pre-texturing (Asoh et al., 2001). As-prepared porous anodic alumina (PAA) membranes are amorphous to X-ray diffraction (XRD). Their chemical composition is not stoichiometric $\mathrm{Al}_{2} \mathrm{O}_{3}$ but incorporates a considerable quantity of anion impurities and hydroxyl groups incorporated from the anodising electrolyte into the alumina structure or bound to the alumina surface (Thompson, 1997).

PAA has proved to be valuable as a template for fabricating many materials, especially for the synthesis of metallic or semiconductor nanometre-scaled wires and particles (Choi et al., 2003; Lombardi et al., 2006; Sander \& Tan, 2003). After chemical functionalising, PAA membranes can be utilised for catalytic (Cho et al., 2005) or optical (de Azevedo et al., 2004) purposes. Further, the porous film itself may be employed for filtration (Sano et al., 2003), gas separation (Lira \& Patterson, 2002) or as a photonic crystal (Masuda et al., 2000). Because it is a ceramic oxide, PAA has considerable potential in high-temperature applications, although problems can occur when certain types of PAA membranes are heated. For example, phosphoric acid-derived membranes tend to buckle or crack when heated above $700^{\circ} \mathrm{C}$, due to high mechanical tension arising from a phosphorus gradient along the pore direction (Brown et al., 2006).

This review details fabrication methodologies for PAA membranes and examines the ceramic chemistry of their physical and chemical structures formed under different anodising conditions. It describes how these structures change in response to thermal treatment, which is important in the context of their use in high temperature applications, 
such as for gas separation technologies. It also examine two specific applications of PAA membranes: their use as templates for the formation of palladium-based ultra-thin film hydrogen gas separation devices, and as host structures for the fabrication of metal nanowire arrays.

\section{Fabrication methodology}

The anodisation of aluminium can be undertaken using a range of acid electrolytes, most commonly oxalic, sulphuric and phosphoric acids, whose conduction and electrochemical characteristics lead to voltage control of the interpore distance, the pore diameter of the fabricated ceramic and the thickness of the barrier layer, a concept first introduced by O'Sullivan and Woods (1970) and later elaborated and refined by many others (eg. Li et al., 1998). These relationships broadly conform to the equations: interpore distance $\sim 2.8 \mathrm{~nm} / \mathrm{V}$, pore diameter $\sim 1.29 \mathrm{~nm} / \mathrm{V}$ and barrier layer thickness $\sim 1.04 \mathrm{~nm} / \mathrm{V}$ although these relationships were developed for a limited set of conditions using $\mathrm{H}_{3} \mathrm{PO}_{4}$ with 80-120 V applied anodisation voltage. Subsequent work indicates that this is a useful guideline but there are plenty of exceptions to these relationship rules. The schematic in Figure 1 broadly summarises our own experience which indicates a general trend of $\sim 2.5 \mathrm{~nm} / \mathrm{V}$ for interpore distance.

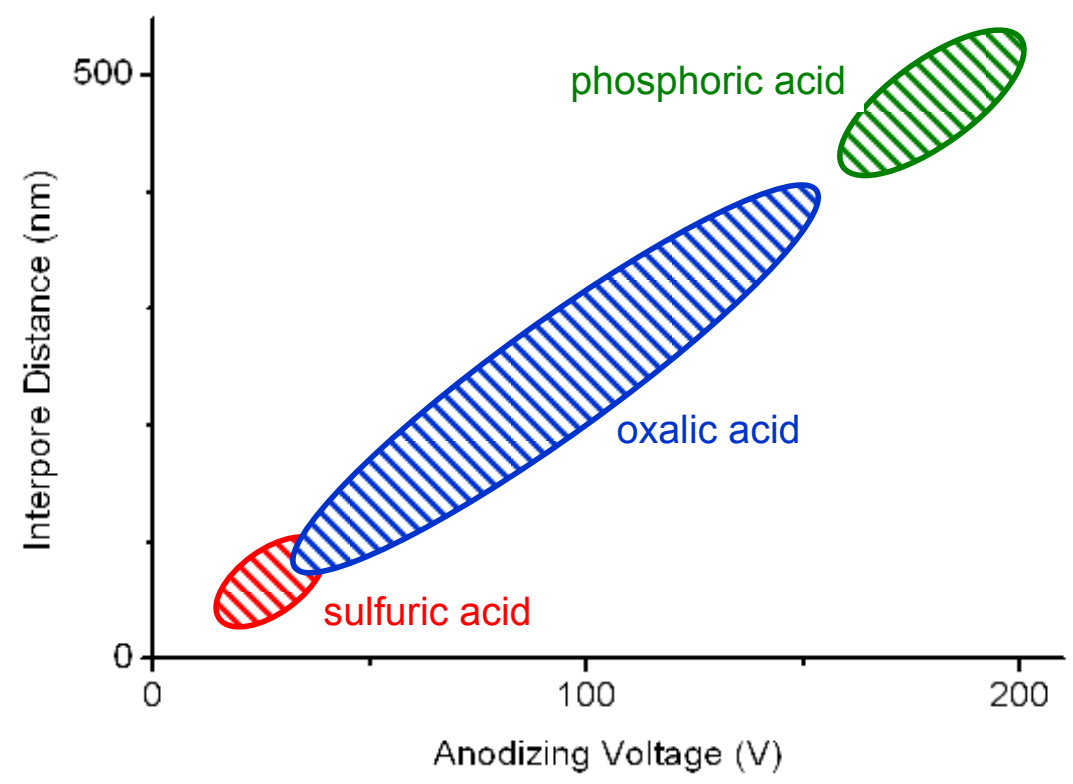

Fig. 1. Schematic relationship between acid electrolyte, voltage and pore structure.

Figure 2 shows a collation of Scanning Electron Microscope (SEM) images illustrating the electrolyte/voltage/pore structure relationship. In this case the four combinations of electrolyte and voltage illustrated show a clear relationship between pore diameter and anodising voltage although this does not conform to the O'Sullivan model, with pore diameter $\sim 0.67 \mathrm{~nm} / \mathrm{V}$ in this case. 


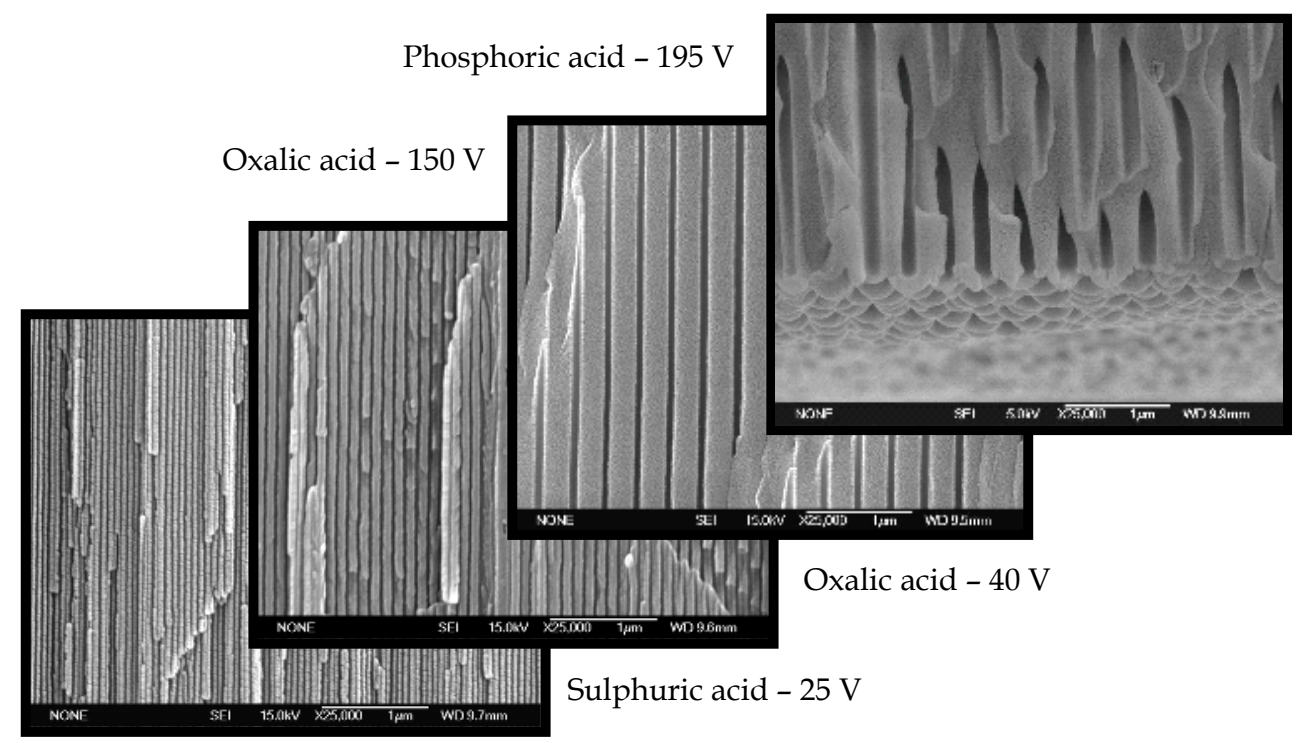

Fig. 2. SEM images showing the relationship between electrolyte, voltage and pore structure.

The selection of acid electrolyte and anodising voltage enables the fabrication of a very wide range of ceramic membrane pore sizes and interpore spacings, all based on the same hexagonal pore topology. This topology is a consequence of self ordering caused by mutual repulsive forces between oxide growth sites in the aluminium metal. Other topologies can be forced by techniques such as nano-indentation patterning of the aluminium foil substrate using tools such as Electron Beam Lithography (EBL) and Focussed Ion Beam (FIB) techniques (Lee et al., 2006a; Robinson et al., 2007). The degree of perfection of pore ordering is usually enhanced by a two step fabrication process. A preliminary anodisation step (either initiated from a nano-indentation site or by self initiation) is terminated early and the resultant film is stripped by acid dissolution, leaving residual etch pits in the metal substrate. These pits form sites which direct the anodic growth during a second anodisation cycle. The electrochemical mechanism of membrane formation has been discussed widely in the literature over many years (see eg. Sulka, 2008) and a simple précis will suffice in this case.

The anodisation process commences with the formation of an ultrathin aluminium oxide barrier layer on the aluminium surface, as electrochemically generated $\mathrm{O}^{2-}$ ions from the electrolyte solution $\left(\mathrm{H}_{2} \mathrm{O}=2 \mathrm{H}^{+}+\mathrm{O}^{2-}\right)$ interact with $\mathrm{Al}^{3+}$ ions released by the electrochemical reaction $\mathrm{Al}=\mathrm{Al}^{3+}+3 \mathrm{e}^{-}$. The barrier layer rapidly reaches a limiting thickness (usually a function of the anodising voltage) at which point roughening or unevenness in the barrier layer develops. Few studies have been undertaken to answer the question as to why roughening occurs at the oxide/electrolyte interface, but it is well known that the pores are initiated from this roughening. The electric field is concentrated in the pits in the oxide/electrolyte interface and pores grow by either field assisted plastic flow of the oxide or by field assisted dissolution. There are two processes in balance during the growth of the characteristic collinear pore structure. The formation of new oxide is offset by the 
dissolution of (older) oxide at a distance from the zone of greatest electric field gradient. This means that the rate of growth slows during anodisation as the distance to the oxide/electrolyte interface increases. In practical terms this imposes a finite limit to the thickness of the PAA layer that can be generated before the dissolution rate balances or exceeds the deposition and growth rate (O'Sullivan \& Wood, 1970).

\subsection{Electrochemical fabrication}

It is common to prepare PAA membranes by direct suspension of shaped aluminium foil pieces in an acid electrolyte. To ensure that anodisation occurs on one side only one $\mathrm{Al}$ face is protected with epoxy or nail polish, which is subsequently stripped following the anodisation chemistry. One such methodology is as follows (Kirchner, 2007a) : Annealed high purity (99.99\%) aluminium foil of $0.25 \mathrm{~mm}$ thickness (Alfa Aesar) was used as a starting material. Pieces $25 \mathrm{~mm} \times 10 \mathrm{~mm}$ were degreased in acetone, coated on one side with ADR246 epoxy (Adhesive Technologies) and cured for $2 \mathrm{~h}$ at $80^{\circ} \mathrm{C}$. In the case of a sulphuric acid electrolyte the specimens were partially immersed in $0.3 \mathrm{M} \mathrm{H}_{2} \mathrm{SO}_{4}$ and anodised for at least $12 \mathrm{~h}$ at a constant potential of $25.0 \mathrm{~V}$ with a platinum cathode. The electrolyte temperature was maintained at $7{ }^{\circ} \mathrm{C}$ by means of a stirred double jacketed vessel connected to a thermostat. After anodising, the epoxy layer was removed using dimethylformamide (DMF).

It has been shown to be practical to use a 'clamp on' cell where the PAA dimension is accurately controlled by an O-ring compression fitting such as shown schematically in Figure 3. In this case a typical methodology is as follows (Brown et al., 2010) : Aluminium foil, $0.25 \mathrm{~mm}$ thick, $99.995 \%$ pure (Alfa Aesar), was cut into $12 \mathrm{~mm}$ strips and cleaned by submersing in ethyl acetate and sonicating for 20 minutes. The cleaned foil was rinsed with distilled water and allowed to air dry. Once dry the strips of foil were cut to produce $12 \times 12$ $\mathrm{mm}$ squares. A schematic of the glass electrolytic cell used for anodisation is shown in Figure 3.

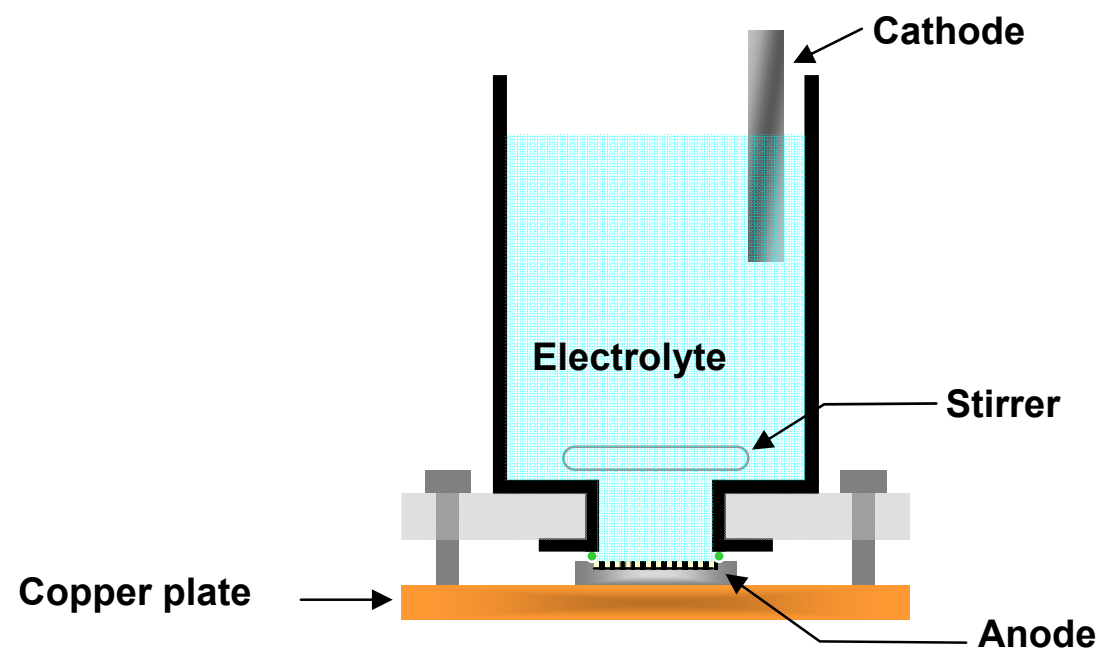

Fig. 3. Schematic of Anodisation Cell. 
In this case the square of aluminium foil is placed directly on a chilled copper plate beneath the stirred electrolytic cell and is clamped in place with an O-ring which exposes an $8 \mathrm{~mm}$ diameter Al foil surface to the electrolyte. A platinum cathode is used and current is transferred to the aluminium anode via the copper plate. The copper plate effectively withdraws the heat dissipated by the electrochemical processing which could otherwise lead to uneven pore growth leaving the membrane unsuitable for further use. To prevent such damage cooling plate is maintained a constant temperature of $3{ }^{\circ} \mathrm{C}$ throughout the anodisation. The design is scalable to larger diameter specimens, conditional upon the need to dissipate process heat, which is both electrolyte and methodology dependent.

PAA membranes can be produced using both so-called 'mild' and 'hard' anodizing techniques (Kirchner et al., 2007a; 2008; Lee et al., 2006b; Brown et al., 2009). For mild anodisation (MA) the voltage is maintained at a minimal level compatible with obtaining alumina growth. For example, with an oxalic acid electrolyte, MA is typically carried out at $40 \mathrm{~V}$. Under these conditions the membrane growth occurs very slowly and it may take a day to prepare a membrane of $100 \mu \mathrm{m}$ thickness. The same thickness can be obtained using hard anodisation (HA) techniques in about two hours. HA uses a much higher voltage to obtain higher current density and an increased rate of alumina growth. HA using an oxalic acid electrolyte is carried out at $150 \mathrm{~V}$. However if the anodisation is commenced at $150 \mathrm{~V}$ the aluminium oxide grows unevenly resulting in an unusable membrane. Successful HA requires formation of a stable barrier layer, which is normally prepared under MA conditions. Once this layer is formed (around 10 minutes) the voltage can be safely increased to that selected for the HA conditions. Figure 4 (left) shows a typical currentvoltage-time profile for $\mathrm{HA}$ using $0.3 \mathrm{M}$ oxalic acid solution as the electrolyte.
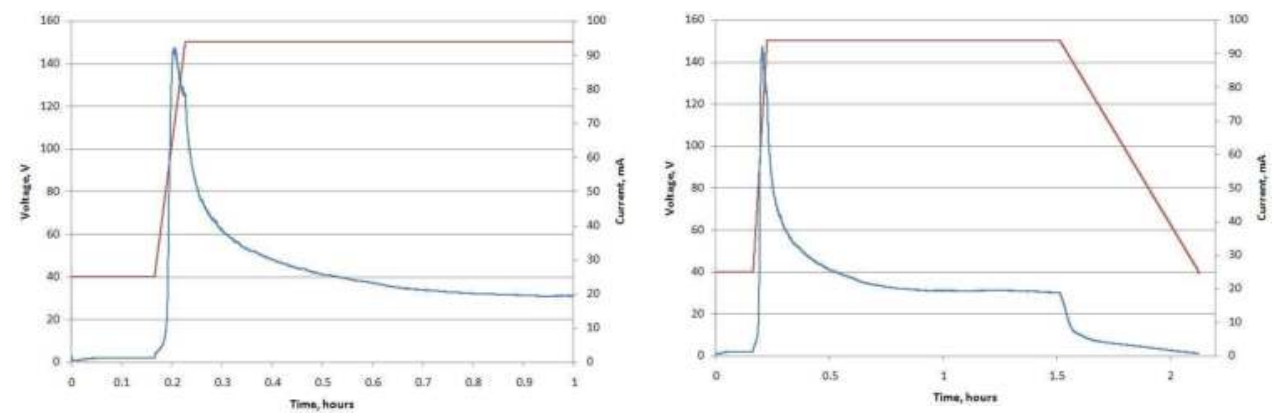

Fig. 4. Current-voltage-time relationships during anodisation, demonstrating progression from mild to hard anodisation conditions (left) and mild-hard-mild conditions (right).

The cell was equilibrated for 20 minutes at $3{ }^{\circ} \mathrm{C}$ prior to commencement of anodisation. The voltage was maintained at $40 \mathrm{~V}$ for 10 minutes, forming a thin barrier layer upon which the remainder of the membrane grows. The voltage was then increased at $0.5 \mathrm{~V} / \mathrm{s}$ to $150 \mathrm{~V}$. The thickness of the membrane is dependent on the amount of charge transferred. Higher voltage allows a greater rate of charge transfer; hence less time is required at a higher voltage to obtain the same thickness of PAA. In this case the voltage was held at $150 \mathrm{~V}$ until $120 \mathrm{C}$ of charge had been transferred (typically $12 \mathrm{~h}$ ) after which the voltage was decreased at a rate of $0.05 \mathrm{~V} / \mathrm{s}$ to $40 \mathrm{~V}$. The $120 \mathrm{C}$ corresponds to a PAA thickness of $120 \mu \mathrm{m}$. During anodisation, the electrolyte was stirred at a constant rate of $250 \mathrm{rpm}$ using a magnetic stirrer. 
The cell design allowed the fabrication of $8 \mathrm{~mm}$ diam. circular PAA discs, which retained their optically transparency even after subsequent detachment, pore widening and thermal procedures (Figure 5).

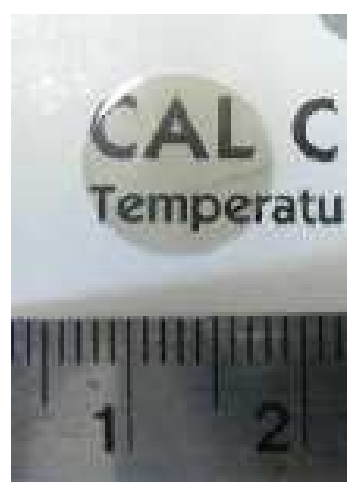

Fig. 5. Transparent PAA template.

Lower voltage (MA) conditions result in slow growth of the membrane, typically a few microns per hour, whereas higher voltage (HA) conditions can lead to growth rates of up to 100 microns per hour. A consequence of this is that conventional pore widening techniques, usually carried out on MA membranes by phosphoric acid etching, can be quite ineffective on the denser and more acid resistant HA substrates (see section 2.3). The development of smart anodisation cycles that incorporate both MA and HA process steps provides a means to mitigate this problem. Figure 4 (right) illustrates how these processes are combined to fabricate membranes in which the final phase of the growth cycle is undertaken using reduced voltage conditions, permitting easier pore opening and widening of the near surface ceramic pore structure.

\subsection{Membrane detachment and pore opening}

The as-anodized PAA membrane remains attached to the aluminium substrate. To obtain free-standing membranes numerous methods have been reported to dissolve or detach the aluminium. In terms of dissolution methods, the use of $\mathrm{HgCl}_{2}$ solutions, although effective, has generally been superseded by dissolution of the remaining aluminium metal in a saturated iodine-methanol (or ethanol) solution at $50^{\circ} \mathrm{C}$ (Kirchner, 2007a). The transparent PAA membranes are rinsed in methanol to clean off excess iodine. PAA fabrication using MA techniques results in relatively slow growth of the alumina template, typically requiring 12-24 h or more to achieve $100 \mu \mathrm{m}$ thickness. Figure 6 shows MA membranes prepared using conditions of $0.3 \mathrm{M} \mathrm{H}_{2} \mathrm{SO}_{4}, 25 \mathrm{~V}, 5{ }^{\circ} \mathrm{C}, 12 \mathrm{~h}$. The membranes were detached using iodine-ethanol dissolution of the residual aluminium metal and in this case the iodine etching process took $12 \mathrm{~h}$. Fig. 6 (left) shows the closed pores on the metal contact (basal) side of the film prior to opening by etching in $5 \% \mathrm{H}_{3} \mathrm{PO}_{4}$ for $60 \mathrm{~min}$ at $30{ }^{\circ} \mathrm{C}$ shown in Fig. 6 (right). During this treatment the opposing face was protected with nail polish, which was subsequently removed with acetone. The hexagonal pore topology is clearly visible in both images. 

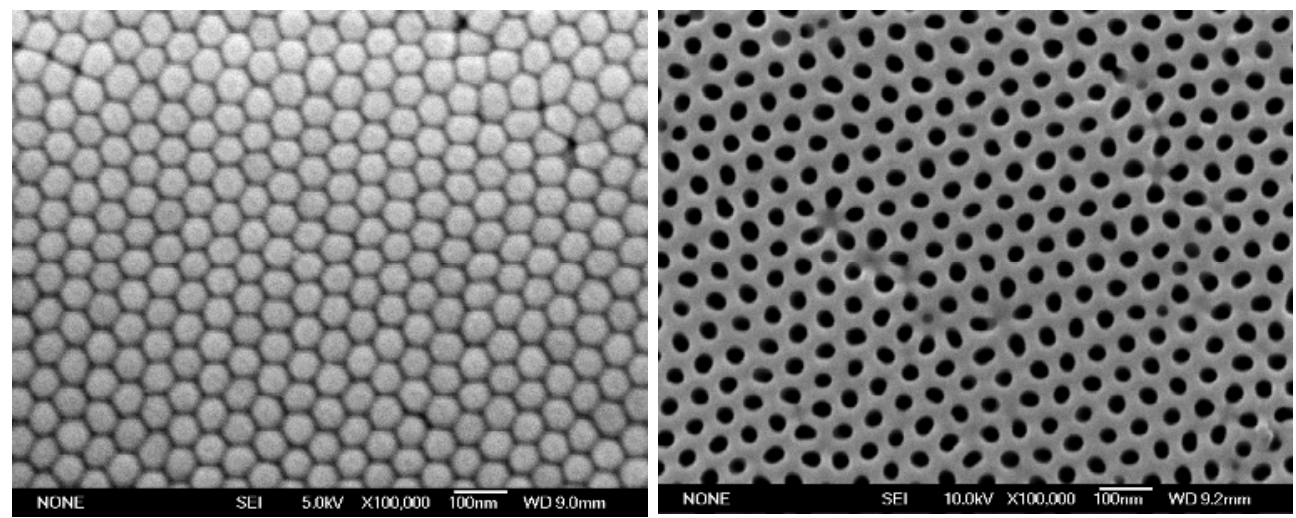

Fig. 6. MA membranes ( $\left.0.3 \mathrm{M} \mathrm{H}_{2} \mathrm{SO}_{4}, 25 \mathrm{~V}, 5^{\circ} \mathrm{C}, 12 \mathrm{~h}\right)$. Left: basal face revealed by iodine etching. Right: Pores opened using $5 \% \mathrm{H}_{3} \mathrm{PO}_{4}\left(60 \mathrm{~min}, 30{ }^{\circ} \mathrm{C}\right)$.

The attraction of employing HA techniques is the relative speed with which a PAA template can be formed, with growth rates typically $100 \mu \mathrm{m} . \mathrm{h}^{-1}$. In this context the $12 \mathrm{~h}$ or so required for iodine etching is a significant issue. To address this, anodisation pulse techniques have been developed (Yuan et al., 2006; Chen et al., 2007; Brown et al., 2008) to accelerate removal of the membrane from the Al substrate. The SEM image in Figure 7 shows a HA specimen prepared in $0.3 \mathrm{M}$ oxalic acid at $6^{\circ} \mathrm{C}\left(40 \mathrm{~V} 10 \mathrm{~min}\right.$, ramp $0.5 \mathrm{~V} . \mathrm{s}^{-1}$ to $150 \mathrm{~V}$, hold for $35 \mathrm{~min}, 90$ $\mathrm{C}$ charge transferred). Following anodisation the oxalic acid electrolyte was discarded and after rinsing the cell with distilled water, was replaced with a $1: 1 \mathrm{HClO}_{4}(60 \%) /$ ethanol solution. The membrane was detached by applying a $175 \mathrm{~V}$ pulse for $15 \mathrm{~s}$. This method has the advantages of being rapid and not requiring any heavy metals which may contaminate the membrane. After the single voltage pulse the perchloric acid-ethanol mixture was removed and the free-standing membrane was rinsed in distilled water. Membranes may be stored in distilled deionised water until further use.
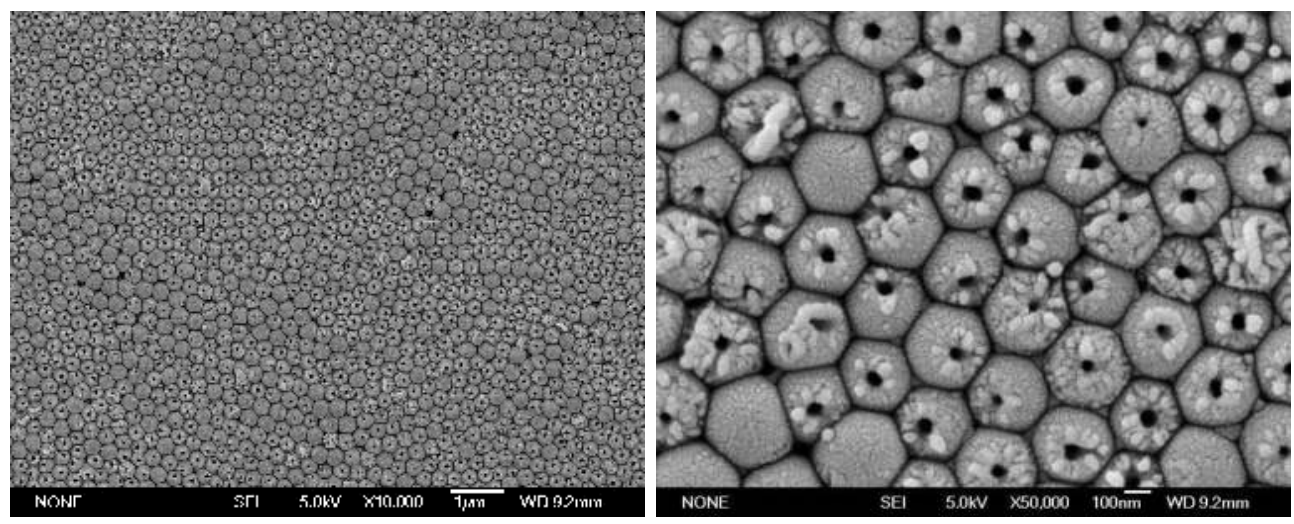

Fig. 7. HA membrane $(0.3 \mathrm{M}$ oxalic acid, $150 \mathrm{~V})$ showing pore opening caused by $175 \mathrm{~V}$ detachment pulse. 
The acid attack on the $\mathrm{Al}$ causes immediate detachment of the membrane. The detachment procedure commences the pore opening process, with a high proportion of the pores shown in Fig. 7 featuring small 'pin-hole' openings near the centre of the basal pore cap. The closeup image shows that this process is accompanied by deposition of considerable alumina debris around the pin-hole. Increasing the detachment voltage to $200 \mathrm{~V}$ appeared to give an increase in the proportion of opened cells. These HA materials are chemically durable and present a considerable challenge to create a uniform open pore cross section, such as required as a template for a hydrogen separation membrane. Subsequent etching of the pulse detached specimens required 30-60 min exposure to $5 \% \mathrm{H}_{3} \mathrm{PO}_{4}$ at $45{ }^{\circ} \mathrm{C}$. These conditions opened most of the pores but created considerable surface roughness, damage and debris on both the basal and electrolyte sides of the membranes. The iodine removal and acid etch procedure on the less chemically durable MA membranes was more controllable and predictable in its outcome. The result of applying these (much slower) processes to HA membranes was unexpected. Figure 8 shows an HA specimen $(0.3 \mathrm{M}$ oxalic acid, $5{ }^{\circ} \mathrm{C}, 20 \mathrm{~mA} / 180 \mathrm{~V}$ ), with $\mathrm{Al}$ removed in iodine solution, etched in $5 \mathrm{wt} \% \mathrm{H}_{3} \mathrm{PO}_{4}$ at 45 ${ }^{\circ} \mathrm{C}$ for $30 \mathrm{~min}$. This shows preferential dissolution at cell junctions with no pore opening at cell centres. To successfully prepare controlled porosity templates using HA processing techniques, a different approach is required in which a low voltage step is introduced at the end of the HA processing (Fig 4 (right)). This effectively creates an MA zone in the vicinity of the barrier layer that is more readily pore-opened.
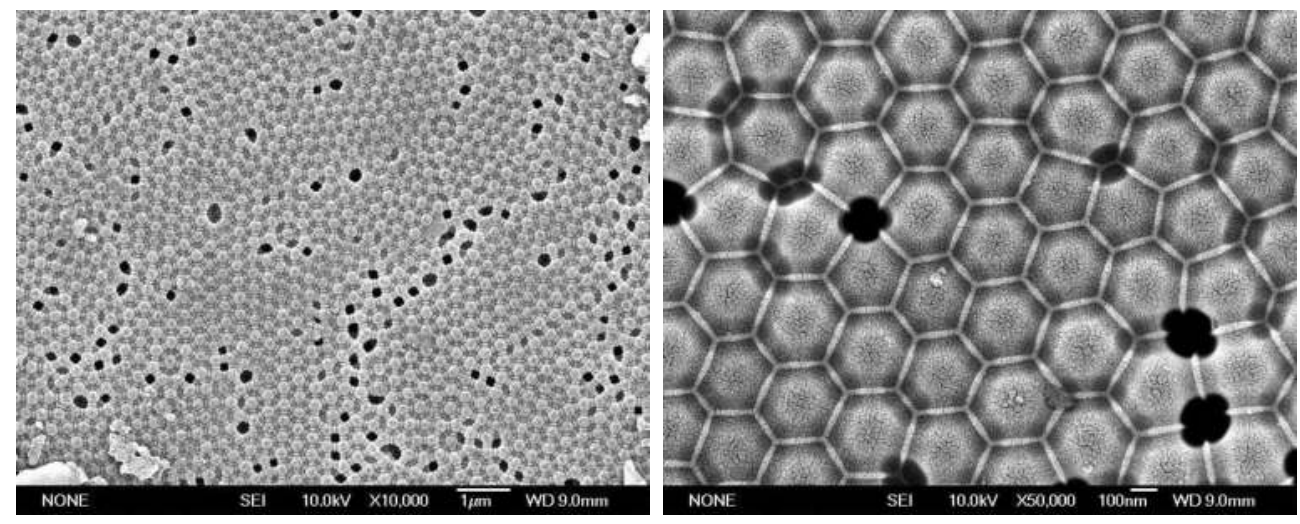

Fig. 8. HA membrane ( $0.3 \mathrm{M}$ oxalic acid, $150 \mathrm{~V})$, Al removed in iodine solution, etched in 5 wt $\% \mathrm{H}_{3} \mathrm{PO}_{4}$, showing preferential dissolution at cell junctions.

Following detachment of the PAA from the aluminium substrate the pores of the PAA are closed at one end. Removal of this barrier layer opens the pores to form continuous collinear channels through the ceramic. In addition to removing the barrier layer the pores may also be widened. MA amorphous alumina membranes are susceptible to attack by acids and bases. Relatively mild conditions can be used to etch the MA membrane to remove the barrier layer and widen the pores.

For materials prepared using a 'mild-hard-mild' anodising sequence such as that illustrated in Fig 4 (right), the small 'mild' section of the membrane is more susceptible to attack by acids than the main body of the membrane prepared under $150 \mathrm{~V}$ 'hard' conditions. By 
initiating and closing the anodising process at $40 \mathrm{~V}$ (in this case) the barrier layer is thus more susceptible to acid attack than the remainder of the membrane so the pore caps can be removed with little impact on the body of the membrane. Membrane etching was undertaken using a $5 \mathrm{wt} \%$ solution of phosphoric acid, placed in a beaker in a water bath maintained at $30^{\circ} \mathrm{C}$. Both the temperature and time of immersion affect the final pore size and structure of the membrane. Immersing the membranes for 60 minutes at $30{ }^{\circ} \mathrm{C}$ was determined as the ideal conditions to remove the barrier layer and partially widen the pores without damaging the structure of the membrane. The PAA membranes were rinsed in distilled water and allowed to air-dry.

\subsection{Hierarchical pore structures}

By integrating various anodisation schemes, a hierarchical pore structure may be formed on a single aluminium substrate. It is possible to increase the pore diameter and spacing, and vice versa during anodisation, but the key is to control the anodisation voltage. The voltage, specific to each acidic electrolyte, determines the pore spacing and the thickness of the barrier layer (O'Sullivan \& Wood, 1970). Hence, any abrupt change in anodisation voltage can result in either a barrier layer that is too thick for charge transfer, so the anodisation stops, or a barrier layer that is too thin to handle the large amount of current, so electric-field assisted dissolution processes dominate.

Figure 9 shows SEM images of the cross-section of PAA templates with a hierarchical pore structure (Wu et al., 2010a). Figure 9 (left) shows a smooth transition in pore structure fabricated using a transition from $0.3 \mathrm{M}$ oxalic acid at $40 \mathrm{~V}-150 \mathrm{~V}$ to $0.1 \mathrm{M}$ phosphoric acid at $160 \mathrm{~V}$ (forming the bottom part of the image - the barrier layer structure). Fig. 9 (right) illustrates a sudden step change from $195 \mathrm{~V}$ (phosphoric acid) to $80 \mathrm{~V}$ (oxalic acid) in pore diameter transition in strong contrast to the progressive change in pore structure as shown in Fig. 9 (left). The temperature and concentration of the acidic electrolyte are extremely important in attaining a smooth transition. An integrated process that allows gradual change in electrolyte type, concentration, and temperature while the anodisation is controlled by a computer-interface is ideal for the fabrication of hierarchical anodic alumina templates.
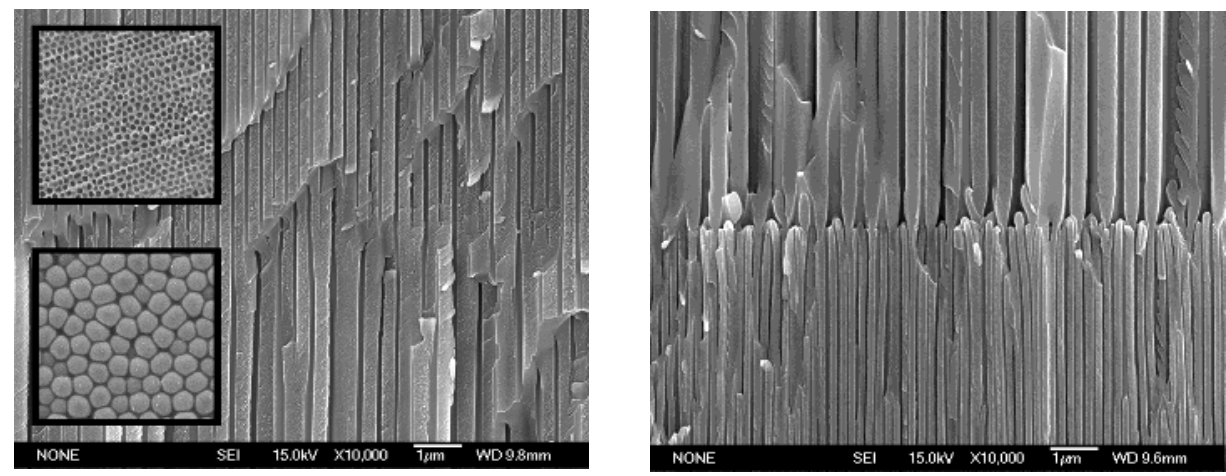

Fig. 9. SEM images of the cross-section of PAA templates with a hierarchical pore structure.

Left. Insets: (top) electrolyte facing side, $0.3 \mathrm{M}$ oxalic at $40 \mathrm{~V}-150 \mathrm{~V}$; (bottom) barrier layer, $0.1 \mathrm{M}$ phosphoric at $160 \mathrm{~V}$.

Right. Sudden step change from $195 \mathrm{~V}$ (phosphoric acid) to $80 \mathrm{~V}$ (oxalic acid). 


\section{Thermal and structural transformations of porous anodic alumina}

Understanding the thermal transformation behaviour of PAA is essential if it is desired to use the PAA materials for high temperature applications such as templates for gas separation devices operating above $300^{\circ} \mathrm{C}$. The principal research tools used to characterise the materials are SEM, XRD, Thermal analysis (DTA/DSC/TGA), Evolved Gas Analysis by Mass Spectrometry and Solid State Nuclear Magnetic Resonance (NMR). XRD and thermal analysis techniques have been used to characterise crystalline phase transitions in PAA prepared in phosphoric acid (Wang et al., 2004), oxalic acid (Mardilovich et al., 1995) and sulphuric acid (Ozao et al., 2001) at temperatures up to $600{ }^{\circ} \mathrm{C}, 1200{ }^{\circ} \mathrm{C}$, and $1250{ }^{\circ} \mathrm{C}$ respectively. Irrespective of the acid electrolyte used during their preparation, the as-formed PAA membranes are X-ray amorphous. During heat treatment, PAA crystallises initially as a metastable transition-alumina phase, finally transforming to the stable hcp a-phase (corundum) at higher temperature.

Magic-angle spinning nuclear magnetic resonance (MAS NMR) is a powerful tool to determine short-range structural changes in poorly crystallised or amorphous inorganic environments (MacKenzie \& Smith, 2002). ${ }^{27}$ Al MAS NMR has been used to study the Al-O coordination environment in as-prepared PAA (Farnan et al., 1989; Iijima et al., 2005; Brown et al., 2006). The as-formed materials show distinctive distributions of 4,5 and 6 coordinated $\mathrm{Al}^{3+}$ in an X-ray amorphous structure which is stable to $>700{ }^{\circ} \mathrm{C}$. The ${ }^{27} \mathrm{Al}$ MAS NMR spectrum of an MA $\left(\mathrm{H}_{2} \mathrm{SO}_{4}\right)$ membrane is shown in Figure 10, showing the contributions from 4, 5 and 6 coordinated species (59.8 ppm, 14\%; 30.9 ppm, 57\%; 3.2 ppm, 29\%, respectively). $\mathrm{AlO}_{5}$ is an extremely unusual coordination environment, and is very similar to that of amorphous $\rho-\mathrm{Al}_{2} \mathrm{O}_{3}$ derived from gibbsite $\left(\mathrm{Al}(\mathrm{OH})_{3}\right.$ ) heated in vacuo (MacKenzie \& Smith, 2002). Typical instrument setup and operating conditions are described by Brown et al., (2006).

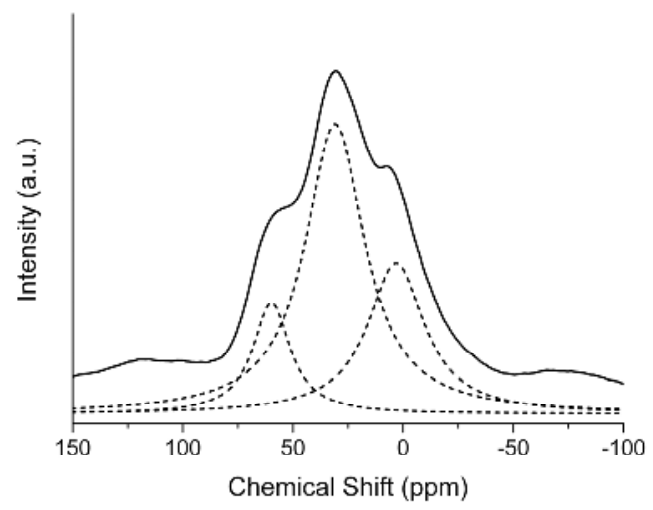

Fig. 10. ${ }^{27} \mathrm{Al}$ MAS NMR spectrum of a heated MA $\left(\mathrm{H}_{2} \mathrm{SO}_{4}\right)$ membrane heated to $200{ }^{\circ} \mathrm{C}$, curve resolved.

Previously reported thermal analysis data (Brown et al., 2006; Kirchner et al., 2007a, 2008) shows that further heating causes a sharp exothermic event due to formation of crystalline transition alumina phase(s). This event occurs at $850{ }^{\circ} \mathrm{C}$ for $\mathrm{H}_{3} \mathrm{PO}_{4}$ electrolyte, $900{ }^{\circ} \mathrm{C}$ for $\mathrm{H}_{2} \mathrm{C}_{2} \mathrm{O}_{4}$ electrolyte and $970{ }^{\circ} \mathrm{C}$ for $\mathrm{H}_{2} \mathrm{SO}_{4}$ electrolyte, although the precise crystallisation 
temperature varies with sample heating rate. The thermal and structural characteristics of PAA prepared using these three acid electrolytes are markedly different and are explored in greater detail in the following sections.

\subsection{Thermal and structural transformations of phosphoric acid membranes}

Phosphoric acid-derived membranes are prepared under high voltage conditions, typically $150-200 \mathrm{~V}$, leading to pore diameters in the 100-200 nm range. Here, we examine the thermal and structural transformations of commercially prepared Whatman Anodisc ${ }^{\circledR}$ alumina membrane filters, fabricated as discs $13 \mathrm{~mm}$ diameter $\times 60 \mu \mathrm{m}$ thick. Such membranes, whether commercially or laboratory prepared, display a particular characteristic, which is that they buckle or curl into a tubular structure when heated above $850{ }^{\circ} \mathrm{C}$ (Brown et al., 2007), thereby limiting (or eliminating) their ability to be used for high temperature applications. In particular, such heating results in a sintering process that leads to closure of the surface pore structure on basal (anode) face of the membrane, shown in Figure 11, although the relics of the original 200nm diameter surface pore structure remain clearly visible.
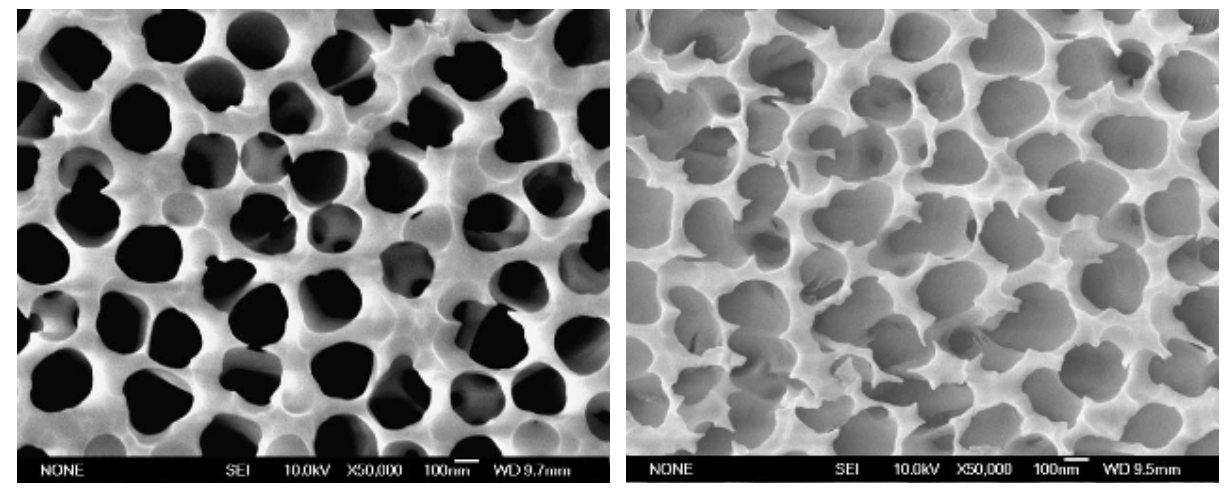

Fig. 11. SEM images of PAA prepared using phosphoric acid electrolyte. (Left) Unheated. (Right) Heated to $1000^{\circ} \mathrm{C}$.

The DSC-TGA data for PAA prepared using phosphoric acid electrolyte is shown in Figure 12. The characteristics are (i) effectively zero weight loss on heating to $1400{ }^{\circ} \mathrm{C}$ and (ii) three significant exothermic events at $850{ }^{\circ} \mathrm{C}, 1020^{\circ} \mathrm{C}$ and $1340{ }^{\circ} \mathrm{C}$, respectively. These events form the basis for heating schedules for XRD and NMR examination.

The XRD sequence is reproduced in Figure 13 and shows the progressive, but slow, development of crystalline phases with increasing temperature. The sequence should be viewed in the context of both the DSC data in Figure 12 and the sequence of $27 \mathrm{Al}$ MAS NMR spectra shown in Figure 14. The XRD trace is completely amorphous until $790{ }^{\circ} \mathrm{C}$, when the first weak reflections begin to appear. By $824^{\circ} \mathrm{C}$ the key peaks of poorly crystallized $\theta-\mathrm{Al}_{2} \mathrm{O}_{3}$ are observed. The short furnace hold time at $824{ }^{\circ} \mathrm{C}$ has been sufficient to push the crystallisation through the $850{ }^{\circ} \mathrm{C}$ exotherm in Fig.12. The second exotherm at $1020{ }^{\circ} \mathrm{C}$ is characterised in the XRD only by the appearance of a strong single peak at $d=4.11 \AA$, which improves in strength and crystallinity with continued heating. No other XRD peaks appear to be associated with this reflection, which is assigned to the cristobalite form of $\mathrm{AlPO}_{4}$ (ICDD 31-0028). 


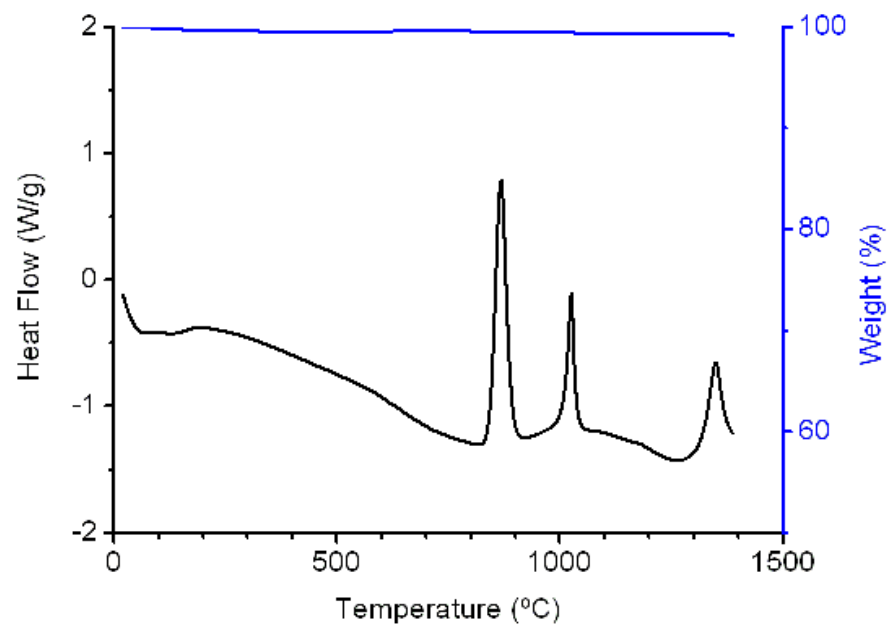

Fig. 12. DSC-TGA data for PAA prepared using phosphoric acid electrolyte.

With increasing heating temperature the first significant change to the NMR spectrum takes place at and above $790{ }^{\circ} \mathrm{C}$ with the development of a strong feature at $4-5 \mathrm{ppm}$, characteristic of 6-coordinated $\mathrm{AlO}_{6}$ structural units. This is followed at and above $824^{\circ} \mathrm{C}$ by a sharp feature at 38-40 ppm, characteristic of well-ordered $\mathrm{AlO}_{4}$ or $\mathrm{AlO}_{5}$ structural units. Both structural events occur ahead of or at the very commencement of the first exothermic DSC peak centred at $850{ }^{\circ} \mathrm{C}$ and underline the value of NMR in identification of the first signs of short range structural ordering in amorphous reaction systems. The vertical compression of Fig. 14 tends to de-emphasize the spectral features that are apparent in Fig. 10 , although the progressive growth and collapse of specific features is evident. The broad peak at 30-32 ppm assigned to $\mathrm{AlO}_{5}$ begins to decline in relative intensity beyond $925{ }^{\circ} \mathrm{C}$ and its elimination appears to be the only significant change in the nature or distribution of ${ }^{27} \mathrm{Al}$ NMR signals that coincide with the second DSC exotherm at $1020^{\circ} \mathrm{C}$. The broad strong peak centred at $63 \mathrm{ppm}$ can be assigned to a range of $\mathrm{AlO}_{4}$ environments that are bonded through neighbouring $\mathrm{AlO}_{6}$ structural units (Müller et al., 1986). The interpretation is consistent with the presence of the transition alumina phases such as $\theta-\mathrm{Al}_{2} \mathrm{O}_{3}$ and potentially $\delta-\mathrm{Al}_{2} \mathrm{O}_{3}$ in which aluminium is distributed equally between octahedral and tetrahedral sites. Significantly, this peak grows in parallel with the strong $\mathrm{AlO}_{6}$ peak centred at 4-5 ppm. Both $63 \mathrm{ppm}$ and $5 \mathrm{ppm}$ peaks are abruptly eliminated by heating above 1295 ${ }^{\circ} \mathrm{C}$. The final $1340{ }^{\circ} \mathrm{C}$ NMR spectrum is dominated by a strong $\mathrm{AlO}_{6}$ peak at $12 \mathrm{ppm}$, characteristic of $\mathrm{a}-\mathrm{Al}_{2} \mathrm{O}_{3}$ (corundum) (MacKenzie \& Smith, 2002).

The first NMR sign of this corundum peak is evident as a distinct shoulder in the penultimate spectrum at $1295^{\circ} \mathrm{C}$. The origin of the small sharp resonance at $38 \mathrm{ppm}$ requires discussion. The peak develops at $824^{\circ} \mathrm{C}$ and becomes increasingly sharp with increasing temperature. The origin of the peak lies in the fabrication methodology of the membrane itself. EDX analytical data (shown in Fig. 15 as a face-to-face phosphorus analysis profile) give an atomic ratio of $2.9: 97.1 \mathrm{P}: \mathrm{Al}$, confirming that the membrane was manufactured in phosphoric acid and that ' $\mathrm{PO}_{4}{ }^{\prime}$ structural units have been incorporated into the alumina ceramic. 


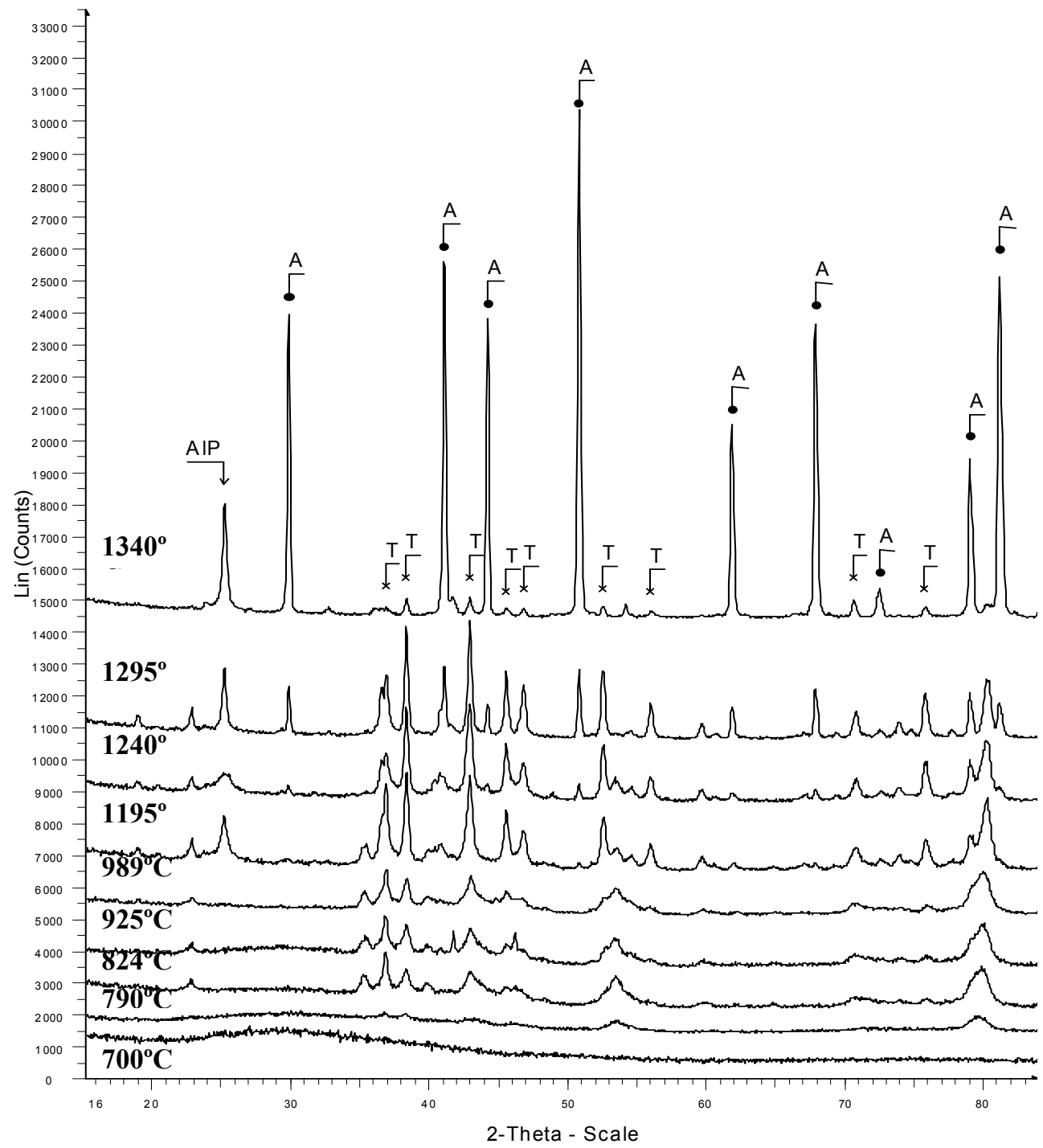

Fig. 13. XRD of heated phosphoric acid-derived PAA. (Key: $\mathrm{AlP}=\mathrm{AlPO}_{4} ; \mathrm{A}=\alpha-\mathrm{Al}_{2} \mathrm{O}_{3} ; \mathrm{T}=$ $\theta-\mathrm{Al}_{2} \mathrm{O}_{3}$. Co $\mathrm{K} \alpha$ radiation). 


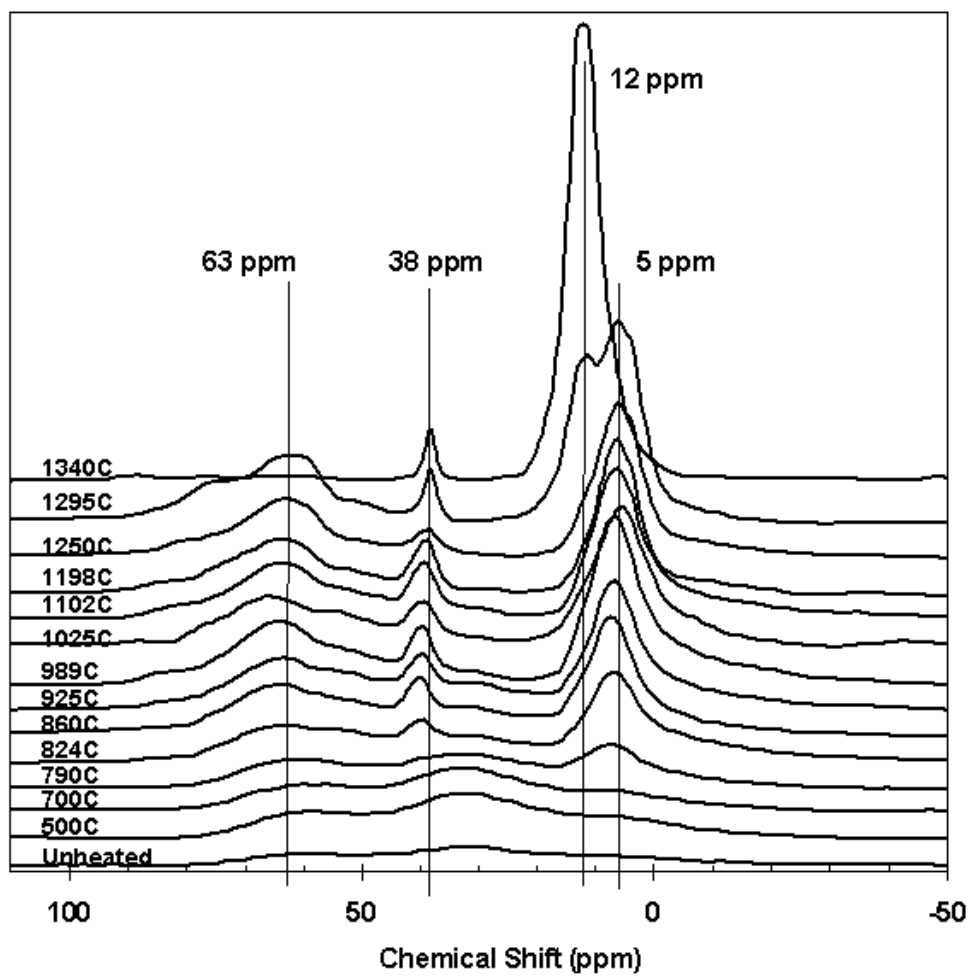

Fig. 14. ${ }^{27} \mathrm{Al}$ MAS NMR spectra of heated phosphoric acid-derived PAA.

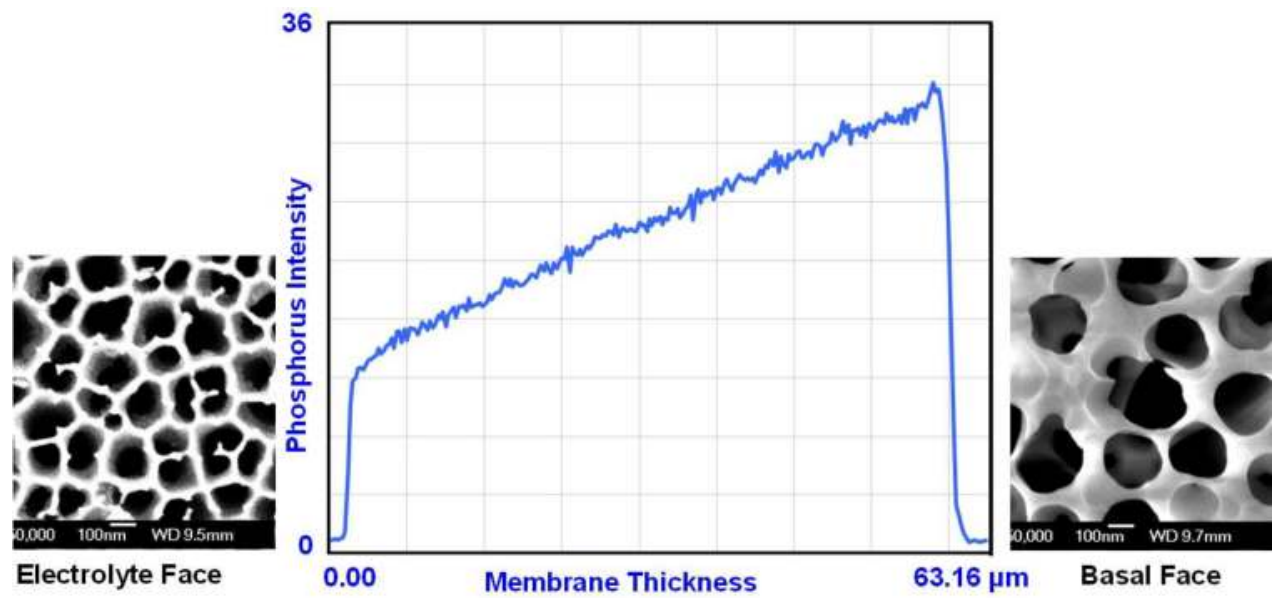

Fig. 15. EDX analysis profile for phosphorus across heated phosphoric acid-derived PAA.

Given this information and the XRD analytical data, the 38 ppm peak can be assigned to tetrahedral $\mathrm{Al}$ in a $\mathrm{Q} 4$ environment, indicating that all $\mathrm{Al}$ is connected through oxygen to $\mathrm{P}$ 
as a next neighbour (Müller et al., 1989). The analysis has been confirmed by ${ }^{31 P}$ NMR examination of both unheated and $1340{ }^{\circ} \mathrm{C}$ specimens. Brown et al., (2006) report that the $1340{ }^{\circ} \mathrm{C} 31 \mathrm{P}$ spectrum displays a strong peak at $28.1 \mathrm{ppm}$, in agreement with previous $\mathrm{AlPO}_{4}$ studies (Müller et al., 1989). The curve fitted area ratio of the $\mathrm{AlO}_{4}\left(\mathrm{AlPO}_{4}\right): \mathrm{AlO}_{6}$ (corundum) NMR peaks at $1340{ }^{\circ} \mathrm{C}$ is 2.7 : 97.3, in excellent agreement with the EDX analysis.

The onset of $\alpha-\mathrm{Al}_{2} \mathrm{O}_{3}$ (corundum) formation is seen in the major XRD reflections by $1195{ }^{\circ} \mathrm{C}$, which, unusually, is ahead of its visibility by NMR. However, the proximity of the strong $\mathrm{AlO}_{6} \mathrm{NMR}$ signal at $5 \mathrm{ppm}$ arising from octahedral $\theta-\mathrm{Al}_{2} \mathrm{O}_{3}$ is certain to have obscured any early observation of corundum crystallisation. By $1340{ }^{\circ} \mathrm{C}$ the corundum phase is dominant, accompanied by residual $\theta-\mathrm{Al}_{2} \mathrm{O}_{3}$ and the minor recrystallised $\mathrm{AlPO}_{4}$ phase.

PAA membranes prepared in phosphoric acid, such as commercially produced Whatman Anodiscs ${ }^{\circledR}$, retain $\mathrm{PO}_{4}{ }^{3-}$ entities in the ceramic structure, forming amorphous $\mathrm{AlPO}_{4}$ which recrystallizes on heating to form the cristobalite structural phase of $\mathrm{AlPO}_{4}$. Not only are the phosphate phases retained in the ceramic on heating to elevated temperatures (above $1300^{\circ} \mathrm{C}$ ) they are distributed asymmetrically across the thickness of the membrane (Fig. 15) resulting in severe loss of membrane planarity on heating above $700{ }^{\circ} \mathrm{C}$.

\subsection{Thermal and structural transformations of sulphuric acid membranes}

Thermal analysis and Evolved Gas Analysis traces for sulphuric acid-derived PAA are shown in Figure 16. In marked contrast to phosphoric acid derived membranes, the heated sulphuric membranes display multi-stage weight loss behaviour and only two exothermic events are seen. Heated specimens generally retain their original planarity.
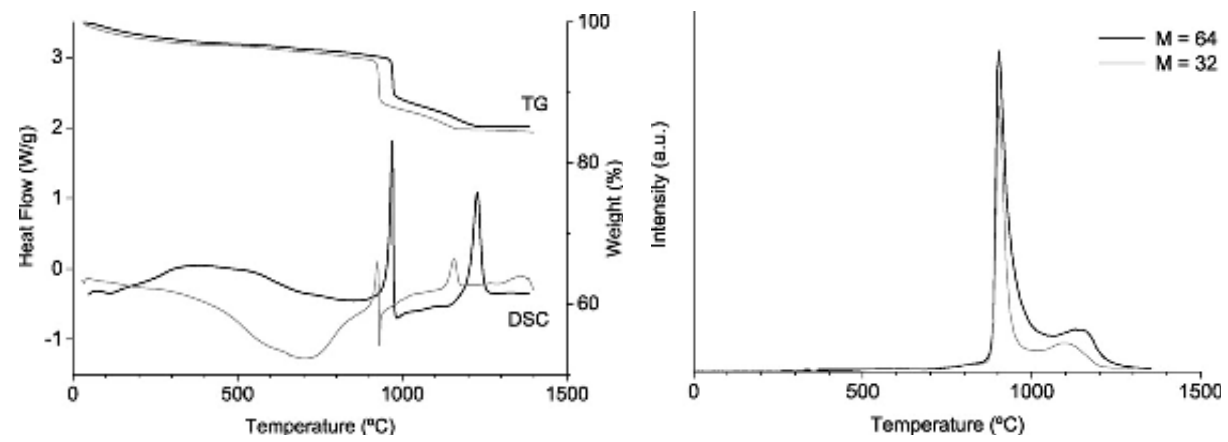

Fig. 16. (Left) DSC (weight-corrected heat flow) and TGA of PAA up to $1400{ }^{\circ} \mathrm{C}$. Black line: scanning rate $20^{\circ} \mathrm{C} / \mathrm{min}$, grey line: scanning rate $2{ }^{\circ} \mathrm{C} / \mathrm{min}$. The DSC signal of the latter is shown 2.5× for clarity. (Right) MS-Signals for mass numbers 64 (black, $\mathrm{SO}_{2}$ ) and 32 (grey, mainly $\mathrm{O}_{2}$ ).

The DSC curve determined at $20^{\circ} \mathrm{C} / \mathrm{min}$ shows a very sharp exothermic peak centred at 970 ${ }^{\circ} \mathrm{C}$ and another slightly broader exotherm centred at $1228^{\circ} \mathrm{C}$. The first exotherm is followed immediately by an endotherm, which is much more marked at low heating rates. These events are irreversible and do not reappear in consecutive heating cycles of the same sample. The thermal analysis data reported by Kirchner et al. (2007a) and Ozao et al. (2001) 
are in good agreement. Decreasing the heating rate to $2{ }^{\circ} \mathrm{C} / \mathrm{min}$ shifted the peak temperatures of the exotherms from $970{ }^{\circ} \mathrm{C}$ to $925^{\circ} \mathrm{C}$ and from $1228{ }^{\circ} \mathrm{C}$ to $1157{ }^{\circ} \mathrm{C}$, respectively, and resulted in a more pronounced endotherm at $930{ }^{\circ} \mathrm{C}$. The heats of transition of the two exotherms were $119 \mathrm{~J} / \mathrm{g}$ and $151 \mathrm{~J} / \mathrm{g}$, respectively. While integration of the high temperature peak is straight-forward, the low temperature result is less reliable due to the partial overlap with the endothermic process. The TGA curve consists of four sections, consisting of a gradual weight loss of $5.0 \%$ from ambient to $950{ }^{\circ} \mathrm{C}$, followed by a very pronounced weight loss of $5.7 \%$ within the next $30^{\circ} \mathrm{C}$. The temperature of the maximum rate of weight loss was $970{ }^{\circ} \mathrm{C}$, coincident with the first exothermic event. In the third section between $980{ }^{\circ} \mathrm{C}$ and $1230{ }^{\circ} \mathrm{C}$ the sample gradually lost 4.2 mass \%. Above $1230{ }^{\circ} \mathrm{C}$ (the temperature of the second exothermic event), the sample weight remained constant.

Mass spectrometry (MS) showed that the strongest signals were from mass numbers 64,32 , and 48 . The mass numbers 64,48 , and 66 had the same temperature profile and were found at a ratio of $100: 55: 5$, consistent with $\mathrm{SO}_{2}$ (Kirchner et al., 2007a). $\mathrm{SO}_{2}$ is also expected to give a mass 32 fragment with approximately $10 \%$ of the intensity of the mass 64 signal. The mass 32 signal observed here was much larger than this, and follows a noticeably different temperature profile from the mass 64 signal (Fig. 16 (right)). The mass signal 32 was therefore interpreted as being composed predominantly of $\mathrm{O}_{2}$. Neither gas species was detected at temperatures below $870{ }^{\circ} \mathrm{C}$, but both reached a maximum at $903{ }^{\circ} \mathrm{C}$, with secondary maxima at $1139{ }^{\circ} \mathrm{C}$ and $1100{ }^{\circ} \mathrm{C}$ for the $\mathrm{SO}_{2}$ and $\mathrm{O}_{2}$ signals, respectively. Furthermore, while $\mathrm{SO}_{2}$ continued to be detected up to $1220^{\circ} \mathrm{C}$, the upper temperature limit for $\mathrm{O}_{2}$ was significantly lower $\left(1180^{\circ} \mathrm{C}\right)$. No signal for mass number 80 , corresponding to $\mathrm{SO}_{3}$, was detected during the experiment.

The XRD data in Figure 17 show that no crystalline phases were detected in sulphuric acidderived PAA samples heated to $\leq 800{ }^{\circ} \mathrm{C}$, comparable with the phosphoric PAA data in Figure 13. Step-wise heating to $900{ }^{\circ} \mathrm{C}$ and $1000{ }^{\circ} \mathrm{C}$ resulted in the formation of ccp $\gamma$-alumina. At $1100{ }^{\circ} \mathrm{C}$, the sample consisted mainly of $\delta$-alumina, with a small amount of a-alumina (corundum). At $1200^{\circ} \mathrm{C}$ only a-alumina was observed in the heated PAA.

The ${ }^{27} \mathrm{Al}$ MAS NMR spectra (Figure 18) indicates that in the as-prepared PAA, as well as in specimens heated to $\leq 800{ }^{\circ} \mathrm{C}$, the aluminium exists in four-, five-, and six-fold coordination, corresponding to the resonances at 55 ppm, 30 ppm, and 7 ppm, respectively (MacKenzie and Smith, 2002). Again, this is comparable to the phosphoric PAA data in Figure 14.

From $900{ }^{\circ} \mathrm{C}$ upwards, the resonance corresponding to five-fold coordination disappeared and the peak corresponding to four-fold coordination shifted to $65 \mathrm{ppm}$. This is characteristic of $\mathrm{AlO}_{4}$ environments bonded through $\mathrm{AlO}_{6}$ structural units (Müller et al. 1986) as found in the cсp $\gamma$-alumina phase. No differences were found between the NMR spectra of the samples heated at $900{ }^{\circ} \mathrm{C}$ and $1000{ }^{\circ} \mathrm{C}$ (containing $\gamma$-alumina) and that of the $1100{ }^{\circ} \mathrm{C}$ sample, shown by XRD to contain principally $\delta$-alumina. There is close structural similarity between the transition-alumina phases $\gamma$ and $\delta$, both of which contain $\mathrm{Al}$ in tetrahedral and octahedral coordination. At $1200{ }^{\circ} \mathrm{C}$ only the octahedral resonance at 11 ppm remains, as expected for hcp a-alumina which a published chemical shift of $12.5 \mathrm{ppm}$ (Farnan et al., 1989; Mackenzie and Smith 2002). Direct comparison between XRD, NMR, DSC/TGA, and MS requires some caution since the dynamics of the heating regimes may impact upon the results. For example, the DSC/TGA results illustrate how the 
transformation temperatures can change with heating rate. The sample preparation for XRD and NMR characterisation experiments involves repetitive heating, with samples quenched once an equilibrium temperature was achieved. This may shift the phase transitions to lower temperatures.

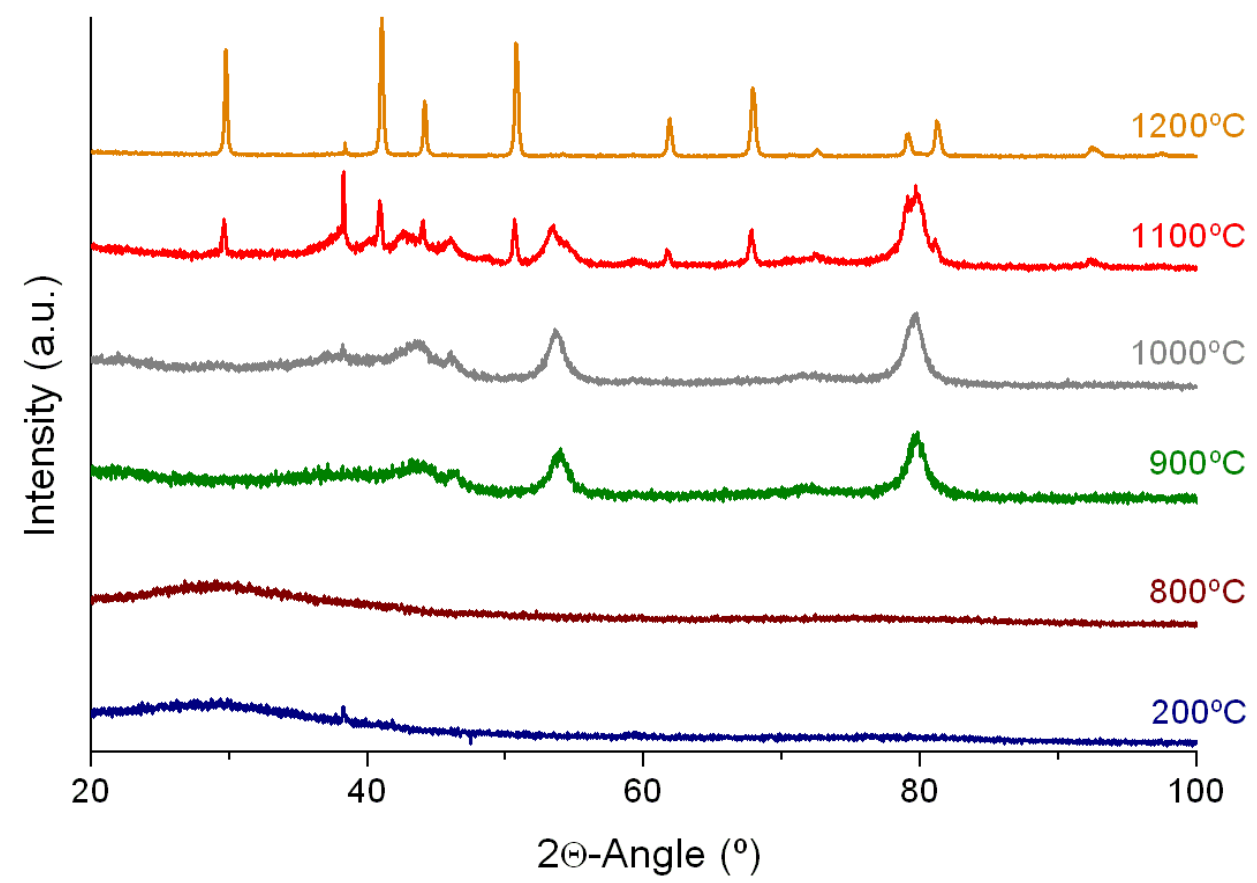

Fig. 17. XRD powder diffraction patterns of sulphuric acid-derived PAA heated to selected temperatures (CoKa radiation).

The complete thermal process can be summarised as follows for a heating rate of $20^{\circ} \mathrm{C} / \mathrm{min}$ : as-prepared PAA contains bound and structural hydroxyl species which are progressively lost with increasing temperature up to the first exotherm at $970{ }^{\circ} \mathrm{C}$. At this point the amorphous alumina crystallises into $\gamma$-alumina. This is linked to a rapid exothermic weight loss caused by decomposition of the sulphate anions with the release of $\mathrm{SO}_{2}$ and $\mathrm{O}_{2}$. This is very similar to the thermal behaviour of $\mathrm{Al}_{2}\left(\mathrm{SO}_{4}\right)_{3} \cdot 16 \mathrm{H}_{2} \mathrm{O}$ which was measured for comparison (Kirchner et al., 2007a). This material shows an endothermic process associated with a weight loss occurring at $900{ }^{\circ} \mathrm{C}$, with MS detection of both $\mathrm{SO}_{2}$ and $\mathrm{O}_{2}$. The release of $\mathrm{SO}_{2}$ from PAA continues up to $1230^{\circ} \mathrm{C}$. The weight loss between $950{ }^{\circ} \mathrm{C}$ and $1230{ }^{\circ} \mathrm{C}(9.9 \%$ of the initial weight) may be attributed solely to the decomposition of $\mathrm{SO}_{4}{ }^{2-}$. No loss of sulphur species was observed by EDX below $800{ }^{\circ} \mathrm{C}$, indicating an initial sulphur content of 4.3 mass \% (allowing for the structural water). This corresponds to a weight loss of $10.7 \%$ (as $\mathrm{SO}_{3}$ ), in agreement with the observed loss above $950{ }^{\circ} \mathrm{C}$. 


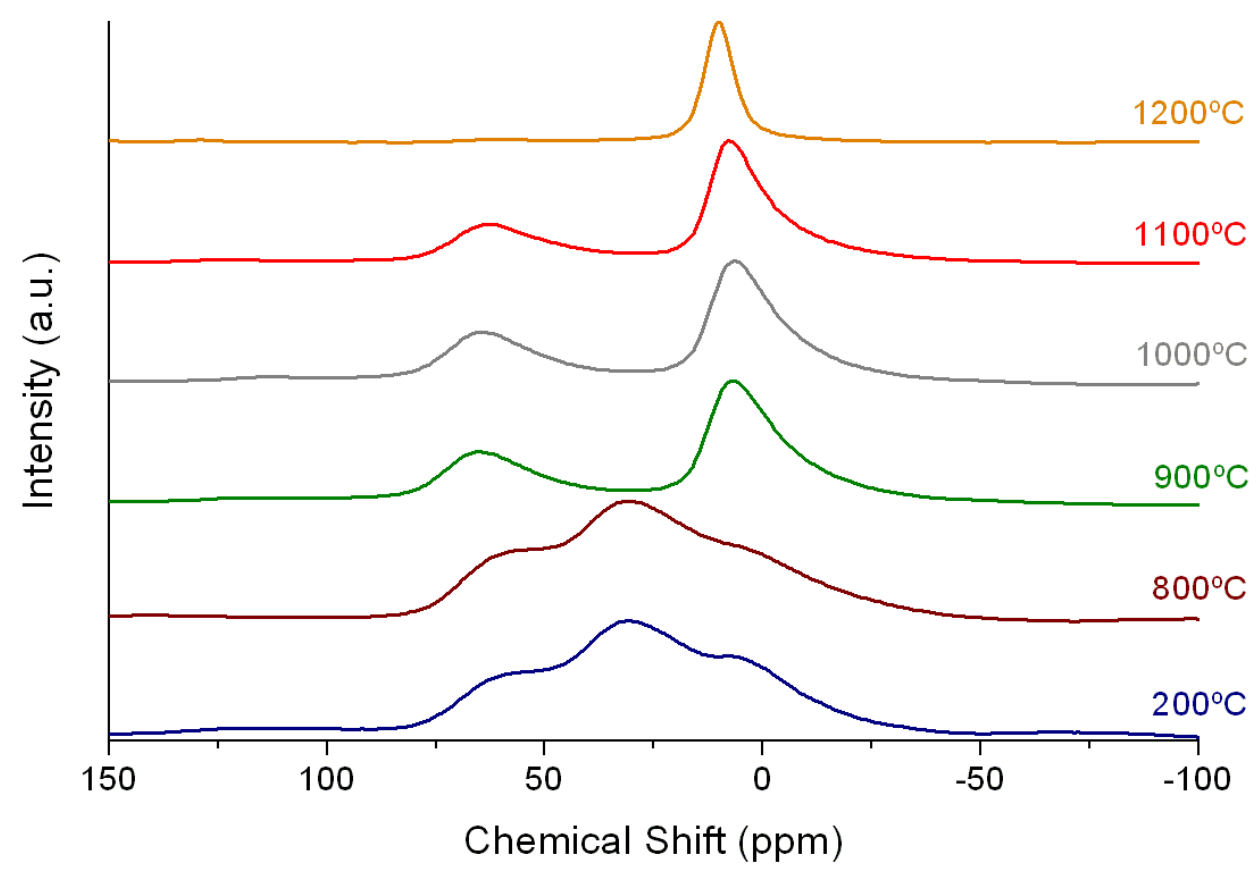

Fig. 18. 11.7 T ${ }^{27} \mathrm{Al}$ MAS NMR spectra of sulphuric acid-derived PAA heated to selected temperatures.

Although the weight loss at the higher temperature can be accounted for by the loss of $\mathrm{SO}_{3}$, the difference in the temperatures at which $\mathrm{O}_{2}$ and $\mathrm{SO}_{2}$ are observed suggests a more complex decomposition mechanism. Since the evolution of $\mathrm{O}_{2}$ clearly ceases before that of $\mathrm{SO}_{2}$ the decomposition reaction is believed to be:

$$
\mathrm{SO}_{4}{ }^{2-} \rightarrow \mathrm{SO}_{3}^{2-}+1 / 2 \mathrm{O}_{2}
$$

The sulphite species remains in the alumina matrix and decomposes subsequently according to the equation:

$$
\mathrm{SO}_{3}^{2-} \rightarrow \mathrm{O}^{2-}+\mathrm{SO}_{2}
$$

At $1228{ }^{\circ} \mathrm{C}$ the alumina undergoes a phase transition to the stable corundum phase. The measured heat for this transition $(151 \mathrm{~J} / \mathrm{g})$ is in reasonable agreement with the theoretical value for the $\delta \rightarrow$ a transition (132 J/g (Chase, 1998)).

The pore architecture observed by SEM following heat treatment is shown in Fig. 19. On heating sulphuric acid-derived PAA membranes to $800^{\circ} \mathrm{C}$, the pore shape and size remain virtually unchanged. No overall shrinkage was observed at temperatures up to $1000{ }^{\circ} \mathrm{C}$ despite the weight loss and crystallisation processes. The basal face (Fig. 19, right) retains its open pore structure, in contrast to the pore closure observed in phosphoric acid membranes (Fig. 11, right). 

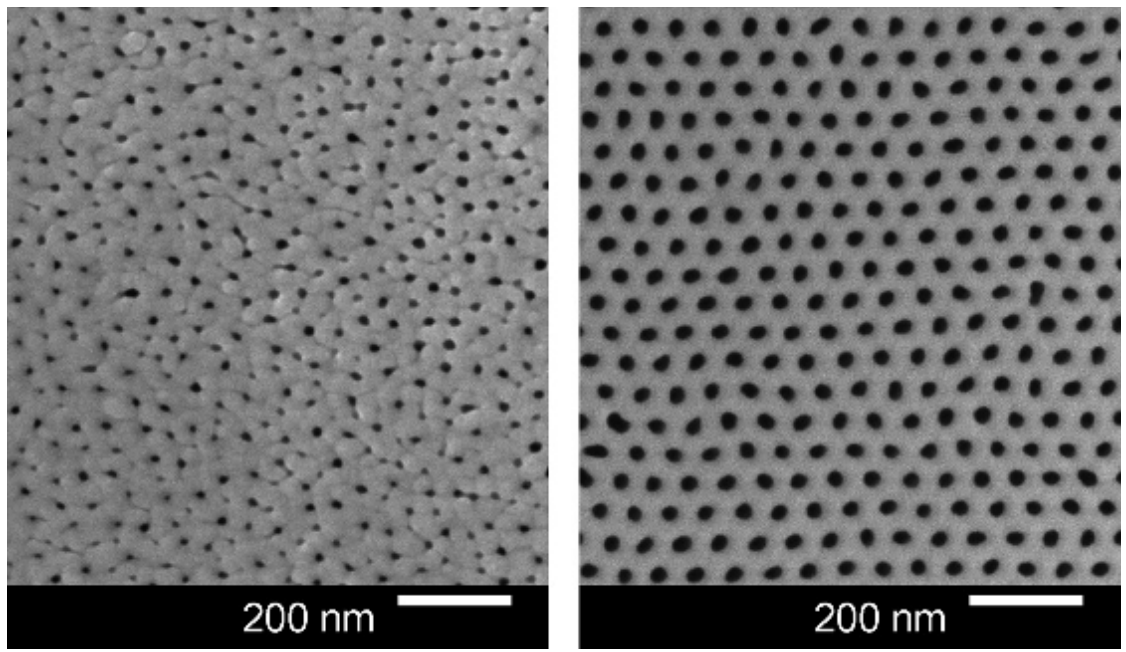

Fig. 19. SEM images of upper (left) and basal faces (right) of a sulphuric acid-derived PAA membrane heated to $800{ }^{\circ} \mathrm{C}$.

\subsection{Thermal and structural transformations of oxalic acid membranes}

The thermal decomposition data for HA PAA oxalic membranes is summarised in Figure 20, which shows evolved gas measurement data superimposed onto the thermal analysis trace. Comparable with sulphuric acid-derived membranes, but in contrast to phosphoric acidderived membranes, $6 \mathrm{wt} \%$ is lost in a sharp exothermic reaction commencing at about $900{ }^{\circ} \mathrm{C}$. Mass Spectrometry (MS) data shows that this is coincident with the loss of $\mathrm{CO}_{2}$ from the alumina lattice. A subsequent exothermic event centred at $1230{ }^{\circ} \mathrm{C}$ represents the

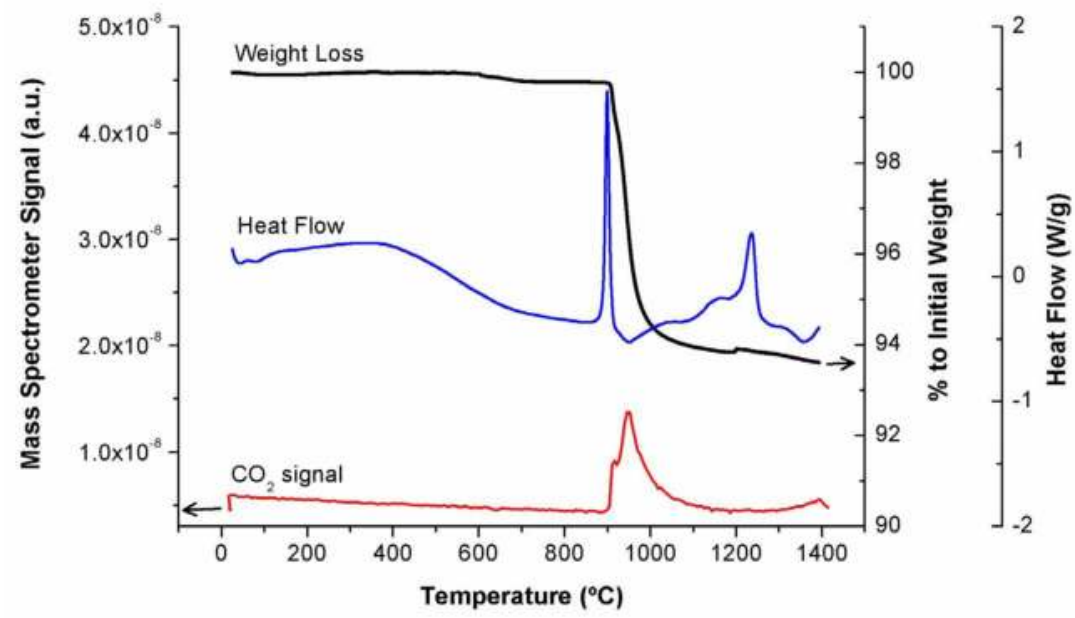

Fig. 20. DSC-TGA data for HA PAA prepared using oxalic acid electrolyte and showing evolved gas Mass Spectrometry data for $\mathrm{CO}_{2}$. 
crystallisation of $\alpha-\mathrm{Al}_{2} \mathrm{O}_{3}$, showing a very similar event sequence to that observed in sulphuric PAA specimens (section 3.2). The MS trace for mass $44\left(\mathrm{CO}_{2}\right)$ shows the possibility of more than one crystallographic site for $\mathrm{CO}_{2}$ decomposition but the absence of events due to mass $32\left(\mathrm{O}_{2}\right)$ suggest a simple, single step decomposition of carbonate ions to carbon dioxide plus retained oxide ions in the alumina matrix, namely $\mathrm{CO}_{3}{ }^{2-} \rightarrow \mathrm{CO}_{2}+\mathrm{O}^{2-}$.

The XRD and ${ }^{27} \mathrm{Al}$ MAS NMR data for heated oxalic acid derived PAA membranes display very similar characteristics to those of the heated sulphuric membranes shown in section 3.2 and are not reproduced here.

\subsection{Summary of thermal and structural transformations of PAA membranes}

It is important to understand the thermally induced structural changes undergone by PAA membranes if these materials are to be used in elevated temperature applications, such as for hydrogen separation devices operating above $300{ }^{\circ} \mathrm{C}$. Irrespective of the acid electrolyte used, all ceramic membranes are X-ray amorphous when first fabricated. They display a unique short range ordering, with a high proportion of 5 coordinated $\mathrm{Al}^{3+}$ in their structure, best revealed and monitored using ${ }^{27} \mathrm{Al}$ MAS NMR techniques. Further, relics of the acid electrolyte used during the anodisation process become chemically bound and remain stable within the alumina structure to temperatures in excess of $850^{\circ} \mathrm{C}$, when their release may be monitored using online Mass Spectrometric gas analysis techniques. The combination of NMR, XRD, MS and Thermal Analysis enables knowledge of a complete picture of the structure and thermal transformations of the membrane from totally amorphous through intermediate transitional alumina structures to a fully crystallized $\mathrm{a}-\mathrm{Al}_{2} \mathrm{O}_{3}$ membrane above $1200{ }^{\circ} \mathrm{C}$.

PAA prepared using phosphoric acid electrolyte shows no weight loss associated with any of the three exothermic events observed on heating through to $1400{ }^{\circ} \mathrm{C}$ but the material distorts badly due to a gradient of $\mathrm{PO}_{4}{ }^{3-}$ species across the thickness of the membrane, which closes off the pores on the basal face. For oxalic acid electrolyte $\sim 6.5 \mathrm{wt} \% \mathrm{CO}_{2}$ is evolved simultaneously with the $900{ }^{\circ} \mathrm{C}$ exotherm, but a planar body and optical transparency are maintained. For $\mathrm{H}_{2} \mathrm{SO}_{4}$ electrolyte the structure takes up high levels of bound $\mathrm{SO}_{4}{ }^{2-}$ and $\mathrm{OH}^{-}$ structural units, with $4.5 \mathrm{wt} \% \mathrm{~S}$ incorporated uniformly across the thickness of the membrane. $\mathrm{OH}^{-}$species are lost from the matrix continuously with heating up to the $970{ }^{\circ} \mathrm{C}$ exotherm at which point rapid weight loss occurs with the release of $\mathrm{SO}_{2}$ and $\mathrm{O}_{2}$ and the formation of $\gamma$-alumina. Similar to oxalic acid, a planar body and optical transparency are maintained above $1000{ }^{\circ} \mathrm{C} . \mathrm{SO}_{2}$ release continues up to the $1230{ }^{\circ} \mathrm{C}$ exotherm that marks the formation of corundum. The $9.9 \%$ weight loss observed between $950{ }^{\circ} \mathrm{C}$ and $1230{ }^{\circ} \mathrm{C}$ is attributed solely to the decomposition of bound $\mathrm{SO}_{4}{ }^{2-}$.

\section{PAA Ceramics as templates for hydrogen separation filters}

The uptake of sustainable hydrogen energy technologies is dependent on many technical, commercial and political factors, but a dominant technology issue is the provision of suitable quantities of high purity hydrogen. Low temperature fuel cells in particular are very sensitive to trace levels of $\mathrm{CO}, \mathrm{SO}_{2}, \mathrm{H}_{2} \mathrm{~S}$ and other impurities in the gas supply, which cumulatively damage and deactivate the electrode catalysts and reduce fuel cell efficiency (Baschuk \& Li, 2003; Uribe et al., 2004). The nanometre scaled collinear pores in these PAA 
ceramic templates provide a means to differentiate gas species in their own right by means of Knudsen controlled diffusion processes (Roy et al., 2003). Expressed simply, if the nanopore diameter is smaller than the mean free path of the gas molecules at the temperature of interest then gas diffusion is controlled by the collisions between the gas molecules and the pore wall rather than by collisions between the gas molecules themselves. Knudsen's relationship states that the gas flux through the pore is inversely proportional to square root of the molecular weight of the gas. Hence, light gases such as $\mathrm{H}_{2}$ and $\mathrm{He}$ will have a much higher flux than $\mathrm{N}_{2}, \mathrm{Ar}, \mathrm{CO}_{2}$ etc. A gas separation system using this concept alone is possible but would behave more like a nanoscaled gas chromatograph than a gas filtration and purification device.

However, membrane filters do provide a means to achieve very high purity hydrogen gas, especially through the use of palladium or palladium alloy materials that provide hydrogenspecific conduction paths (Flanagan \& Sakamoto, 1993; Paglieri, 2006). Hydrogen diffusion through these membrane filters is a multistep process: dihydrogen molecules adsorb onto the surface of the Pd membrane and dissociate into hydrogen atoms, which then diffuse through the interstitial octahedral sites in the fcc Pd lattice and reform as gaseous diatomic hydrogen on the exit face of the palladium membrane. Palladium has a high level of hydrogen permeability while remaining impermeable to other gases, which makes it ideal for the separation of hydrogen from gas mixtures. Difficulties arise because palladium hydride exists in two different phases, $\alpha$ and $\beta$, both fcc structured as in the parent metal. When hydrogen is absorbed into $\mathrm{Pd}$ below $300{ }^{\circ} \mathrm{C}$ the high hydrogen capacity $\beta$ hydride $\mathrm{PdH}_{0.67}$ predominates. Formation of this phase results in a $10 \%$ volume expansion causing stress on the Pd metal lattice and resulting in embrittlement and delamination of the material on repeated adsorption-desorption cycling (Goods \& Guthrie, 1992; Bhat et al., 2009). However at temperatures above $300{ }^{\circ} \mathrm{C}$ the lower hydrogen capacity a hydride phase $\mathrm{PdH}_{0.02}$ predominates and the volume expansion upon adsorption of hydrogen is very small. Consequently, Pd films used in the presence of hydrogen are useful membrane materials only at temperatures above $300{ }^{\circ} \mathrm{C}$.

The introduction of other metals to form palladium based alloys has had promising results. In particular doping of the palladium with silver has been shown to improve the stability of the film and increase the solubility of hydrogen. Further, the temperature above which the a palladium hydride occurred was lowered with increasing silver content (Uemiya et al.,1991; Kikuchi \& Uemiya, 1991). The hydrogen permeability was optimized when the silver content of the alloy was around $23 \mathrm{wt} \%$. Silver occupies interstitial sites in the palladium lattice and so moderates the lattice expansion and contraction due to hydrogen absorption/desorption.

The fabrication of ultrathin Pd and Pd-Ag films supported by robust and thermally stable nanoscaled ceramic membranes offer specific advantages, including fast hydrogen transport via reduced diffusion path lengths through the metal and significantly reduced costs through reduction in the quantity of precious metal used. This section describes the fabrication of nanoscaled membranes by deposition of ultrathin $\mathrm{Pd}$ and Pd-Ag films on durable ceramic templates fabricated using hard anodisation (HA) techniques (Lee et al., 2006; Kirchner et al., 2007b; Brown et al., 2008). Section 4.2 describes methods to control plating to obtain a $\mathrm{Pd}: \mathrm{Ag}$ ratio of approximately $75: 25$; sections 4.3 and 4.4 describe alloying and thermal cycling of the composite membrane and section 4.5 and demonstrates efficient hydrogen separation using these membranes. 


\subsection{Heat treatment}

To ensure that the membranes could withstand exposure to highly basic plating solutions they were heat treated after pore opening to convert the amorphous alumina to $\gamma$-alumina. This was achieved by increasing the temperature at $10{ }^{\circ} \mathrm{C} / \mathrm{min}$ to $890{ }^{\circ} \mathrm{C}$ and holding for 5 minutes before cooling over four hours. $\gamma$-alumina is able to withstand the high $\mathrm{pH}$ plating solutions without damage to the chemical or physical structure of the membrane. Heat treatment to $890^{\circ} \mathrm{C}$ also mitigates the risk of membrane cracking due to thermal expansion mismatch when curing glass seals used for gas test samples at $860^{\circ} \mathrm{C}$. As noted above, most test membranes prepared for use as high temperature gas filters were fabricated using HA techniques to enhance resistance to high $\mathrm{pH}$.

\subsection{Metal deposition on PAA membranes}

Pure palladium films undergo hydrogen embrittlement when maintained in a hydrogen containing atmosphere at temperatures below $\sim 350{ }^{\circ} \mathrm{C}$. The introduction of alloying metals such as silver has been shown to decrease the degree of hydrogen embrittlement and increase the hydrogen permeability of the coating. Palladium and silver containing films can be fabricated either by co-deposition or by individual deposition. In both cases the resulting film must be heat treated to alloy the silver and palladium.

A number of different methods can be used to plate PAA with metals. The electroless methodology of Brown et al., (2010) described here is easy to apply and more economic than the more typical electroplating methods. Electroless plating involves using a reducing agent to reduce metal ions in solution to the elemental metal. For electroless plating to be efficient and successful the surface of the membrane must be seeded with palladium crystals so that the reduced metal has a growth site (Mardilovich et al., 1998). If this activation is not undertaken the reduced metal will form on any available surface within the container. Activation also ensures rapid growth of the metal coating, decreasing the time required for plating. This method of activation is commonly used to prepare surfaces for electroless plating (Collins \& Way, 1993; Mardilovich et al., 1998). The three solutions used for activation are a sensitizing solution consisting of $\mathrm{SnCl}_{2} \bullet 2 \mathrm{H}_{2} \mathrm{O}\left(1 \mathrm{~g} \mathrm{~L}^{-1}\right)$ and $\mathrm{HCl}(33 \%)(1 \mathrm{~mL}$ $\left.\mathrm{L}^{-1}\right)$; an activation solution consisting of $\mathrm{PdCl}_{2}\left(0.1 \mathrm{~g} \mathrm{~L}^{-1}\right)$ and $\mathrm{HCl}(33 \%)\left(1 \mathrm{~mL} \mathrm{~L}^{-1}\right)$; and a solution of $0.01 \mathrm{M} \mathrm{HCl}$. The sensitizing solution should be freshly made before use, since insoluble $\mathrm{Sn}(\mathrm{OH}) \mathrm{Cl}$ forms over time via the reaction scheme in equation (1). Hydrochloric acid is added to the solution to extend the amount of time for the precipitation to occur by increasing the concentration of the products.

$$
\mathrm{SnCl}_{2}+\mathrm{H}_{2} \mathrm{O} \rightarrow \mathrm{Sn}(\mathrm{OH}) \mathrm{Cl}+\mathrm{HCl}
$$

The membranes are attached to plastic holders using a small amount of double-sided tape, then immersed in solution one for five minutes, then rinsed with distilled water. This sensitization step deposits tin (II) hydroxide particles onto the membrane surface. The sensitized membranes are then immersed in the activation solution for five minutes, during which the tin (II) hydroxide particles reduce the Pd (II) to Pd metal via equation (2). The membrane is then briefly immersed in a dilute acid solution to prevent the hydrolysis of the freshly deposited palladium. The entire sensitization and activation process is repeated six times to obtain a sufficient coating of Pd to seed the electroless plating process. 


$$
\mathrm{Pd}^{2+}+\mathrm{Sn}^{2+} \rightarrow \mathrm{Pd}^{0}+\mathrm{Sn}^{4+}
$$

An electroless plating method is used for all co-deposition and individual depositions. Electroless plating involves use of a plating solution containing a metal salt and stabilizing agents. A reducing agent is added just prior to plating which causes the metal salt to reduce to the elemental metal. $25 \mathrm{~mL}$ of the plating solution is placed in a plastic cup in a water bath heated at $60^{\circ} \mathrm{C}$. Once equilibrated, hydrazine is added to the solution which is stirred briefly before submerging the membrane in the solution. The samples are left for varying times depending on the desired thickness of the coating. The time was varied in the case of metal individual deposition to control the palladium to silver ratio of the coating. After plating has been completed the samples are rinsed in distilled water and allowed to dry. Palladium and silver can be co-deposited onto the PAA membranes using electroless plating solutions containing different ratios of $\mathrm{Pd}$ and $\mathrm{Ag}$. Co-deposition has the advantage of interspersing the $\mathrm{Pd}$ and $\mathrm{Ag}$ particles resulting in increased intermetallic contact and more effective alloying (Cheng \& Yeung, 1999). A range of plating solutions were used composed of different $\mathrm{Pd}: \mathrm{Ag}$ ratios. The metal salts used were $\left(\mathrm{NH}_{3}\right)_{4} \mathrm{Pd}\left(\mathrm{NO}_{3}\right)_{2}$ and $\mathrm{AgNO}_{3}$ and the amount used of each was varied to give solutions with different ratios of $\mathrm{Pd}$ and $\mathrm{Ag}$ whilst maintaining a metal concentration of $10 \mathrm{mM}$. The overall composition of the solutions and the detailed methodology is not reproduced here (see Brown et al., 2010; Wu et al., 2010b).

Individual deposition of the $\mathrm{Pd}$ and $\mathrm{Ag}$ was also undertaken using an electroless method. By plating each metal individually the process can be controlled to obtain a range of different metal ratios. Again, the compositions of the plating solutions and the deposition methodology have been detailed elsewhere (Brown et al., 2010; Wu et al., 2010b). The components of the solutions were the same as the co-deposition solutions except for palladium where a chloride salt was used in place of the nitrate. Membranes that were coated with Pd only were used to compare with the bimetallic sample. Samples were also plated with Pd then sequentially with $\mathrm{Ag}$ as comparisons for the co-deposited samples.

Activation is used to seed the surface of the PAA membrane with palladium grains to form sites for growth of the palladium coating during electroless plating. The sensitization step deposits tin hydroxide particles on the surface of the PAA. During immersion in the activation solution the tin hydroxide particles reduce the palladium to palladium metal which then deposits on the surface of the membrane. No tin hydroxide residue remains on the surface of the PAA after activation. The surface of an activated PAA membrane is shown in Figure 21.

Co-deposition of $\mathrm{Pd}$ and $\mathrm{Ag}$ is desirable as it creates a layer of interspersed $\mathrm{Pd}$ and $\mathrm{Ag}$ grains, which aids alloying. A ratio of Pd:Ag 75:25 was sought based on previous work (Kikuchi \& Uemiya, 1991) which reported that an alloy content of 23\% Ag had the most selective hydrogen permeability, and the lowest critical temperature. Experiments were carried out using a number of plating solutions with different Pd:Ag ratios. All solutions gave an even coverage of $\mathrm{Pd}$ and Ag. EDX analyses carried out on samples plated for 30 minutes in solutions containing Pd:Ag 75:25 and Pd:Ag 50:50 showed that the films had a higher Ag content than that of their parent solution; eg. for the 75:25 solution the composition of the coating after 60 minutes was 63:37. This phenomenon has been previously reported (Cheng \& Yeung, 1999) and indicates that Ag is preferentially plated, resulting in Ag enrichment. A Pd : Ag 90 : 10 solution examined using EDX analysis showed 
that a $90: 10$ film co-deposited for 60 minutes resulted in a $\mathrm{Pd}: \mathrm{Ag}$ ratio of $73: 27$. This inconsistency prompted comprehensive EDX mapping analyses (Brown et al., 2010) which confirmed that Ag is deposited first in nodes on the PAA surface followed by a slower build-up of $\mathrm{Pd}$ in the area around the nodes, indicating that modifying the duration of plating will affect the ratio of $\mathrm{Pd}$ to $\mathrm{Ag}$ in the film. It was also observed that fresh solutions gave more reproducible results than aged solutions, so all gas test samples were prepared using freshly made solutions. SEM analysis and gas leak testing (in a cell similar to that described in section 4.5) indicated that a minimum of 30 mins. deposition time was required to ensure a uniform and even coat with no pinholes.
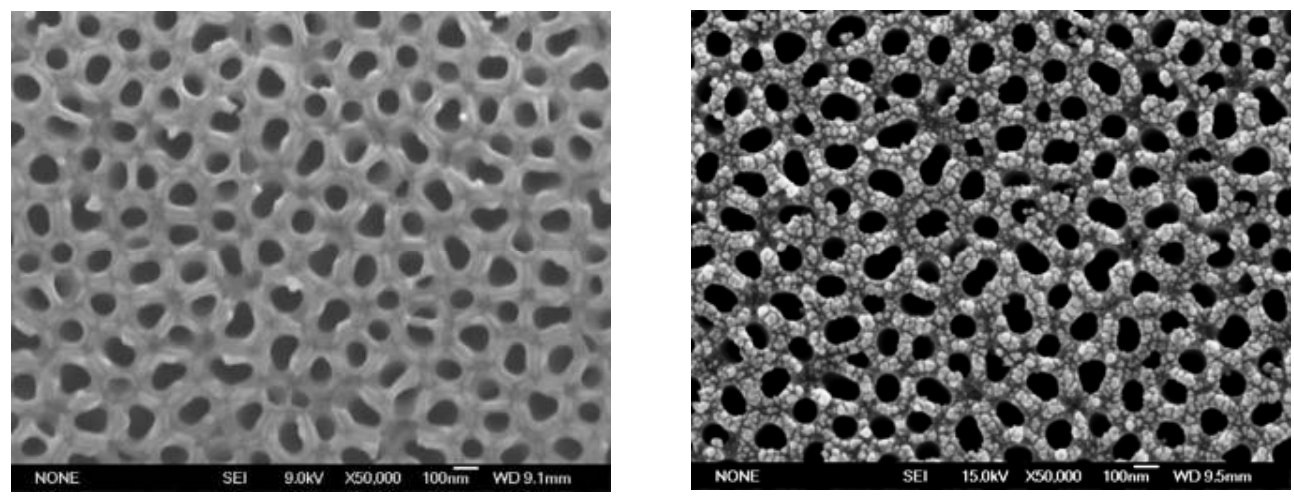

Fig. 21. SEM image of PAA membrane before (left) and after (right) activation. Scale bar is $100 \mathrm{~nm}$.

\subsection{Alloying}

Freshly plated samples containing both $\mathrm{Pd}$ and $\mathrm{Ag}$ phases were alloyed to assess the influence of the addition of silver on the gas separation and thermal stability behaviour of the films. The optimised alloying conditions required heat treatment to be undertaken in forming gas $\left(5 \% \mathrm{H}_{2}\right.$ in $\left.95 \% \mathrm{~N}_{2}\right)$ at $500{ }^{\circ} \mathrm{C}$ for $12 \mathrm{~h}$. The success of the heat treatment was determined by XRD as shown in Fig. 22. The 'as-plated' scan of a pre-alloyed sample (Fig. 22 (left)) shows two discrete phases, with major peaks at approx. $44.6^{\circ} 2 \theta$ and $47^{\circ} 2 \theta$ due to $\mathrm{Ag}$ and Pd respectively. The 'post heat treatment' scan shows successful alloying revealed by a single peak at approx. $45.5^{\circ} 2 \theta$. The position of the alloyed peak can be used as a tool to estimate the relative proportions of $\mathrm{Pd}$ and $\mathrm{Ag}$ in the alloy, as demonstrated in the XRD patterns in Fig. 22 (right).

The surfaces of two different samples after alloying are shown in the SEM images in Fig. 23. These samples were heat treated under Ar to $550{ }^{\circ} \mathrm{C}$ for $12 \mathrm{~h}$. The surface of the membranes show islands of alloyed metal surrounding areas where the metal is no longer present. This indicates that while the metal covered the PAA surface completely after plating, this amount of metal is insufficient to cover the surface after alloying. As a result the gas test samples were plated for multiple and longer times to ensure complete coverage after alloying. The desired coverage was achieved by lengthening the plating time to $90 \mathrm{~min}$. as can be seen in the Pd: Ag $90: 10$ sample (Fig. 23, right). 

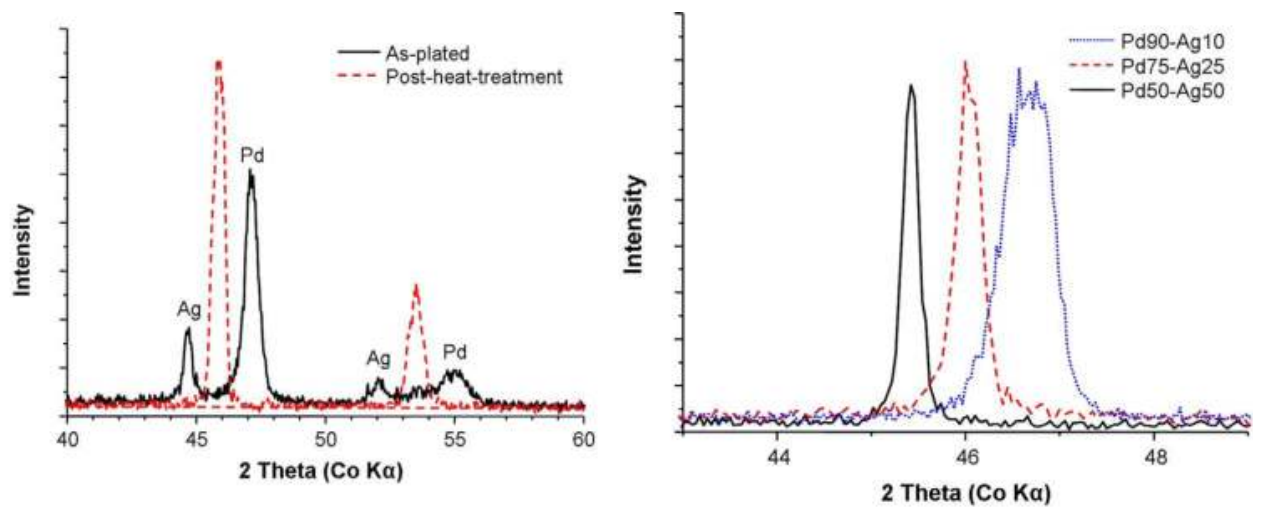

Fig. 22. XRD scans. Left: before and after alloying co-deposited Pd : Ag 50 : 50; Right: Alloyed co-deposited Pd : Ag $50: 50\left(45.4^{\circ}\right), 75: 25\left(46.0^{\circ}\right)$ and $90: 10\left(46.7^{\circ} 2 \theta\right)$.
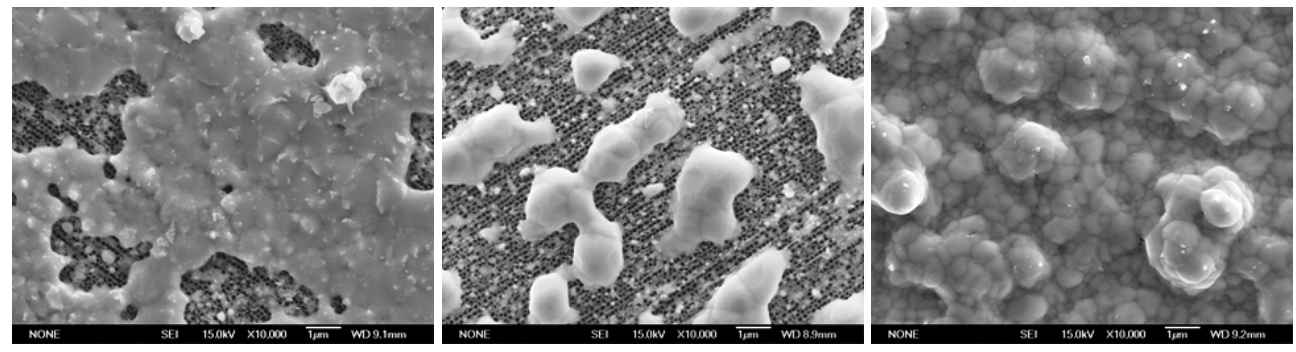

Fig. 23. SEM images of membrane surfaces after alloying: Left: Pd : Ag 50 : 50, 30 min; Centre: 75 : 25, $30 \mathrm{~min}$; Right: $90: 10,60 \mathrm{~min}$.

\subsection{Thermal cycling}

Thermal cycling tests were carried out to determine the relative stability of pure Pd film and Pd : Ag 75 : 25 co-deposited films. The PAA membranes were plated for $1 \mathrm{~h}$, one with Pd only and one co-deposited with Pd : Ag 75 : 25 co-deposition solution. Following deposition, the bimetallic membrane was alloyed by heating to $500{ }^{\circ} \mathrm{C}$ for $12 \mathrm{~h}$ in forming gas. The $\mathrm{Pd}$ only and alloyed membranes were tested simultaneously. The membranes were placed in a tube furnace under $5 \% \mathrm{H}_{2}$ in $\mathrm{N}_{2}$ gas. After gas equilibration in the chamber the furnace was ramped to $400{ }^{\circ} \mathrm{C}$ at $10{ }^{\circ} \mathrm{C} / \mathrm{min}$, the sample was held was $400{ }^{\circ} \mathrm{C}$ for $10 \mathrm{~min}$. before cooling to $100{ }^{\circ} \mathrm{C}$ at $50{ }^{\circ} \mathrm{C} / \mathrm{h}$. The program was repeated to give a total of six cycles. The SEM results shown in Fig. 24 indicate a substantial difference between the membranes. The Pd-only membrane developed large cracks across the surface, whilst the bimetallic sample has no obvious defects. Before cyclic testing, the Pd : Ag, $75: 25$ co-deposited membrane had large nodes of silver on the surface (Fig 24, centre). The cyclic test has caused these to become less crystalline and more rounded in appearance. While it is possible that over time this change may cause defects in the membrane, the addition of silver to the membrane has increased the thermal stability and as a result the life of the membrane. 

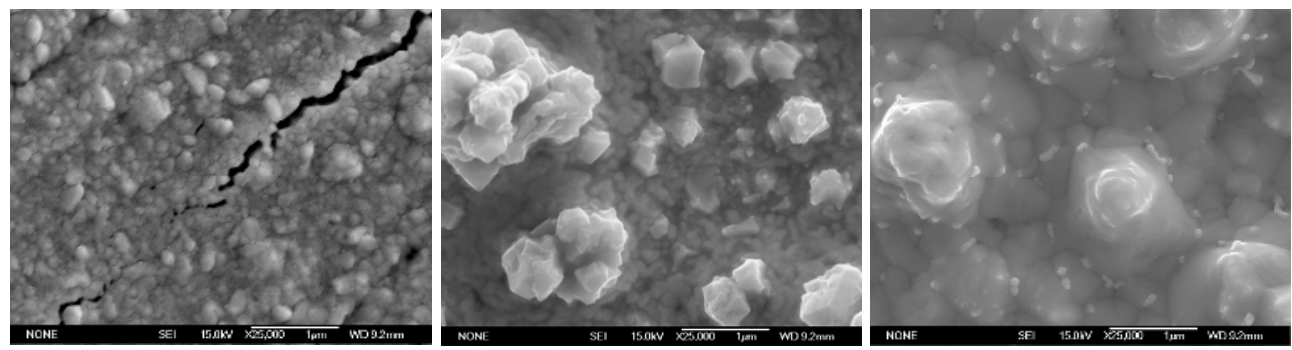

Fig. 24. SEM images of membrane surfaces after thermal cycling. Left: Pd only, after cycling; Centre: Pd : Ag 75 : 25, before cycling; Right: Pd : Ag $75: 25$, after cycling.

\subsection{Gas separation devices}

The samples used for gas separation require additional preparation. Following heat treatment at $900{ }^{\circ} \mathrm{C}$ the PAA membrane was mounted onto a ceramic ring, with a $5 \mathrm{~mm}$ central hole to allow the passage of gases. The PAA membrane was mounted over this ring using a glass seal, which was cured by heat treatment at $860^{\circ} \mathrm{C}$ via ramping at $10{ }^{\circ} \mathrm{C} / \mathrm{min}$, holding at $860{ }^{\circ} \mathrm{C}$ for $10 \mathrm{~min}$ then cooling over $4 \mathrm{~h}$. The heat treatment to $900{ }^{\circ} \mathrm{C}$ was carried out prior to mounting the membrane onto the disc. During this treatment the ceramic was converted from amorphous alumina to $\gamma$-alumina. This thermal pre-treatment was necessary to eliminate any ceramic distortion which might otherwise result in cracking at the glass-ceramic interface due to thermal expansion mismatch during treatment at $860{ }^{\circ} \mathrm{C}$. The glass sealant can be used up its softening temperature of $\sim 860^{\circ} \mathrm{C}$. After the membrane was mounted onto the ceramic disc the activation and plating steps were carried out as normal. The ceramic disc was covered in tape during the activation and plating to limit the metal coating to the PAA substrate. Gas separation tests were carried out using a rig shown schematically in Fig. 25.

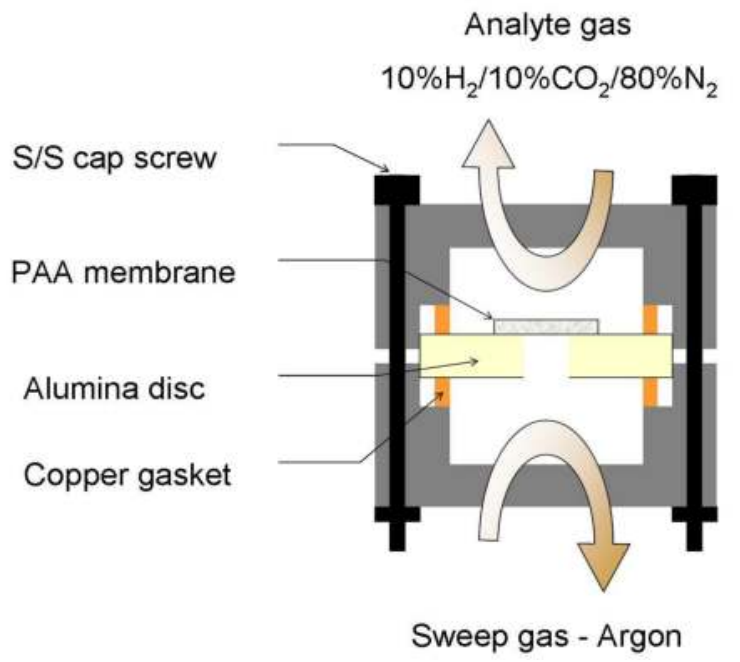

Fig. 25. Schematic of Gas Separation Cell. PAA membrane is $8 \mathrm{~mm}$ dia. for scale. 
An alumina ceramic support disc with the PAA mounted on it was placed between two copper rings inside a stainless steel rig. Copper rings were used because the high malleability of copper allowed the apparatus to be gas tight. Prior to the gas tests the copper rings were softened by heating to $900{ }^{\circ} \mathrm{C}$ and were also polished to ensure a good contact surface. The two halves of the stainless steel rig were clamped together using six stainless steel cap screws. The copper rings and stainless steel bolts were replaced before each test. The entire rig was placed inside a tube furnace to provide accurate temperature control.

The analyte gas was a hydrogen-containing mixture consisting of $10 \% \mathrm{H}_{2}, 10 \% \mathrm{CO}_{2}$ and $80 \%$ $\mathrm{N}_{2}$. The pressure was increased on the analyte side of the membrane using a bubbler. The increased pressure assists the diffusion of hydrogen through the membrane and encourages diffusion in one direction only. An argon sweep gas was used on the exit side of the membrane. After flowing through the cell the sweep gas was analyzed online by mass spectrometry. Prior to the gas separation test the rig was leak tested to ensure integrity of the coating and sealant. Leaks through the membrane and glass seal do occur at a minimal level as indicated by the occasional observation of signals for mass $28\left(\mathrm{~N}_{2}\right)$ and mass 44 $\left(\mathrm{CO}_{2}\right)$ in the mass spectrometry results. Gas tests were carried out on co-deposited Pd:Ag 90:10, 80:20 and 75:25, a sequentially deposited sample and a Pd only sample summarised in Table 1.

\begin{tabular}{|c|c|c|}
\hline Plating Method & Ratio Pd:Ag & Plating Time \\
\hline Co-deposition & $90: 10$ & $2 \times 90 \mathrm{~min}$. \\
\hline Co-deposition & $80: 20$ & $75 \mathrm{~min} .+85 \mathrm{~min}$. \\
\hline Co-deposition & $75: 25$ & $2 \times 75 \mathrm{~min}$. \\
\hline Individual & Pd only & $2 \times 60 \mathrm{~min}$. \\
\hline Individual & $78: 22$ & Pd $75 \mathrm{~min} . \mathrm{Ag} 2 \times 20 \mathrm{~min}$. \\
\hline
\end{tabular}

Table 1. Gas Test Samples.

The gas test samples were put through a thermal cycling procedure. Once the mass spectrometer signals for the various gases had reached equilibrium at room temperature the temperature was increased to $600^{\circ} \mathrm{C}$ over $24 \mathrm{~h}$. The furnace was then cooled to $50^{\circ} \mathrm{C}$ over 12 $\mathrm{h}$ before heating to $600{ }^{\circ} \mathrm{C}$ over $24 \mathrm{~h}$ and cooling to $50^{\circ} \mathrm{C}$ again. The final cycle was from $50{ }^{\circ} \mathrm{C}$ to $700^{\circ} \mathrm{C}$. The Pd:Ag 90:10 sample was heated in $50{ }^{\circ} \mathrm{C}$ intervals allowing $30 \mathrm{~min}$. at each temperature for the mass spectrometer signals to stabilize before taking a reading. This process was used to follow a similar heating schedule to $500{ }^{\circ} \mathrm{C}$ then $550{ }^{\circ} \mathrm{C}$, returning to 50 ${ }^{\circ} \mathrm{C}$ by cooling between the heating cycles. The final ramp from $200-700{ }^{\circ} \mathrm{C}$ was undertaken using a steady heating rate for $36 \mathrm{~h}$. The temperature schedule for the Pd only membrane was an exception to this program. As noted in the introduction to section 4, Pd undergoes hydrogen embrittlement if heated in a hydrogen containing atmosphere below $\sim 300{ }^{\circ} \mathrm{C}$. Hence, the schedule for $\mathrm{Pd}$ involved heating to $350{ }^{\circ} \mathrm{C}$ under a nitrogen or argon atmosphere then switching to the $10 \% \mathrm{H}_{2} / 10 \% \mathrm{CO}_{2} / \mathrm{N}_{2}$ analyte mixture. The mass spectrometer signals were allowed to settle overnight and the following day the sample was heated between 350 and $550^{\circ} \mathrm{C}$ over $8 \mathrm{~h}$. The sample was then cooled to $350{ }^{\circ} \mathrm{C}$ over $4 \mathrm{~h}$ and heated back to $550{ }^{\circ} \mathrm{C}$. The sample was finally cooled to $100{ }^{\circ} \mathrm{C}$ still under the hydrogen containing atmosphere. 
Gas separation tests involve heating the samples at a constant rate while exposed to a hydrogen-containing gas mix $\left(10 \% \mathrm{H}_{2} / 10 \% \mathrm{CO}_{2} / 80 \% \mathrm{~N}_{2}\right)$ and analyzing the composition of the $\mathrm{Ar}$ sweep gas using mass spectrometry. $\mathrm{H}_{2}$ or other gases flowing through the membrane are picked up by the sweep gas and seen by the mass spectrometer. The rig used was not ideal and some analyte gas was able to enter the sweep gas by flowing past the ceramic support disc. As such a slight baseline level for $\mathrm{H}_{2}, \mathrm{CO}_{2}$ and $\mathrm{N}_{2}$ is present in the data. The Pd-only results shown in Fig. 26 (left) have no data between room temperature and $350{ }^{\circ} \mathrm{C}$ as the membrane was heated under a $\mathrm{H}_{2}$ free atmosphere in this temperature window to prevent embrittlement. Above $350{ }^{\circ} \mathrm{C}$ the $\mathrm{H}_{2}$ flux (permeance) increases significantly while the $\mathrm{N}_{2}$ and $\mathrm{CO}_{2}$ fluxes remain at a minimal level.

The Pd:Ag 90:10 co-deposited specimen was sealed effectively with minimal leaks. Though there is some variability in the data (Fig. 26 (right)), overall the $\mathrm{H}_{2}$ flux increases with increasing temperature, while the flux of both $\mathrm{N}_{2}$ and $\mathrm{CO}_{2}$ remain stable at a minimal level, essentially at the detection limit of the mass spectrometer. Up to $\sim 350{ }^{\circ} \mathrm{C}$ the $\beta$ hydride phase dominates and these results show that above $350{ }^{\circ} \mathrm{C}$ there is a more rapid increase in $\mathrm{H}_{2}$ flux through the membrane with accelerated transport through the a phase. This increase in $\mathrm{H}_{2}$ flux above $350{ }^{\circ} \mathrm{C}$ is consistent with the results for the Pd only membrane (Fig. 26 (left)) indicating that increasing the Ag content to 30\% (by EDX) has no detrimental effect on the $\mathrm{H}_{2}$ selectivity.
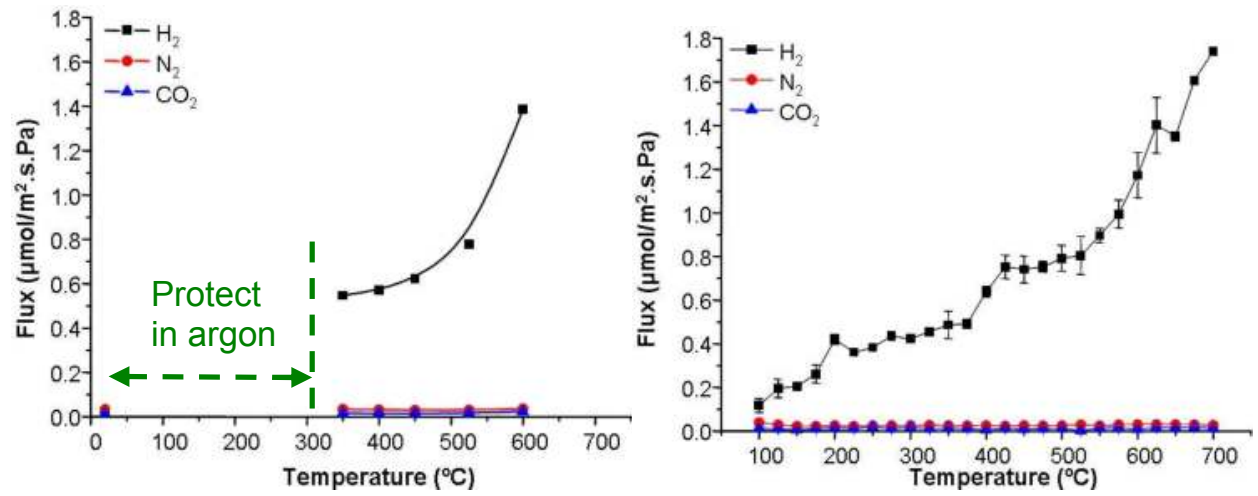

Fig. 26. Mass Spectrometer gas separation results for Pd membrane (left) and Pd : Ag $90: 10$ membrane (right).

Data for the Pd : Ag $80: 20$ and $75: 25$ co-deposited samples (not reproduced here) show that the change in $\mathrm{H}_{2}$ permeance is much less dramatic than for the $80: 20$ and $75: 25$ samples however the measured permeance does increase steadily with temperature to $\sim 1.0$ $\mu \mathrm{mol} / \mathrm{m}^{2}$.s.Pa at $700{ }^{\circ} \mathrm{C}$, compared to with $\sim 1.8 \mu \mathrm{mol} / \mathrm{m}^{2}$.s.Pa for the $90: 10$ membrane (Fig. 26 (right)). This is most likely a result of the increased Ag content in the Pd:Ag $80: 20$ and 75 : 25 materials. An ideal Ag content of $\sim 23 \mathrm{wt} \%$ has been shown to display the highest $\mathrm{H}_{2}$ selectivity and thermal stability (Kikuchi \& Uemiya, 1991). The actual Ag content in both of the $80: 20$ and $75: 25$ films is higher than this $23 \mathrm{wt} \%$ ideal and as such the films will be more thermally stable than those with higher Pd content. However, these higher Ag content alloys should also display reduced $\mathrm{H}_{2}$ permeance, as shown in this data. EDX analysis 
indicated that the composition of the $90: 10$ film was actually close to the desired $23 \mathrm{wt} \% \mathrm{Ag}$ content so the $\mathrm{H}_{2}$ permeance might be expected to increase compared to that of the Pd-only membrane, although the present data at $600{ }^{\circ} \mathrm{C}$ (Fig. 26) shows little distinction in flux.

The method used for these gas separation tests involved several cycles of heating and cooling, as previously noted. Each of these membranes shows a degree of thermal stability over the three cycles as no increase in $\mathrm{N}_{2}$ or $\mathrm{CO}_{2}$ was observed indicating no damage to the film. The results described here (Wu et al., 2010b) are those for the third (final) cycle of each of the tests and it is important to note that the flux increased considerably between cycles, indicating that greater benefit may well be obtained following more extended thermal cycling.

\section{PAA Ceramics as templates for the growth of metal nanowires}

Electrodeposition of conductive materials into PAA templates to form nanowire structures is readily undertaken under potentiostatic conditions, where the deposition rate remains constant and the deposited nanowires grow linearly with time. Based on the total measured amount of charge transferred and the approximate total volume of the nanowires, the electroplating process is $100 \%$ efficient when compared to the theoretical values. By measuring the charge transferred over a specific deposition time, the theoretical volume of material reduced in a $100 \%$ efficient process can be calculated. Thus, the height of the nanowires can be controlled and adjusted precisely. Figure 27 shows nickel metal nanowires electrodeposited in a PAA template.
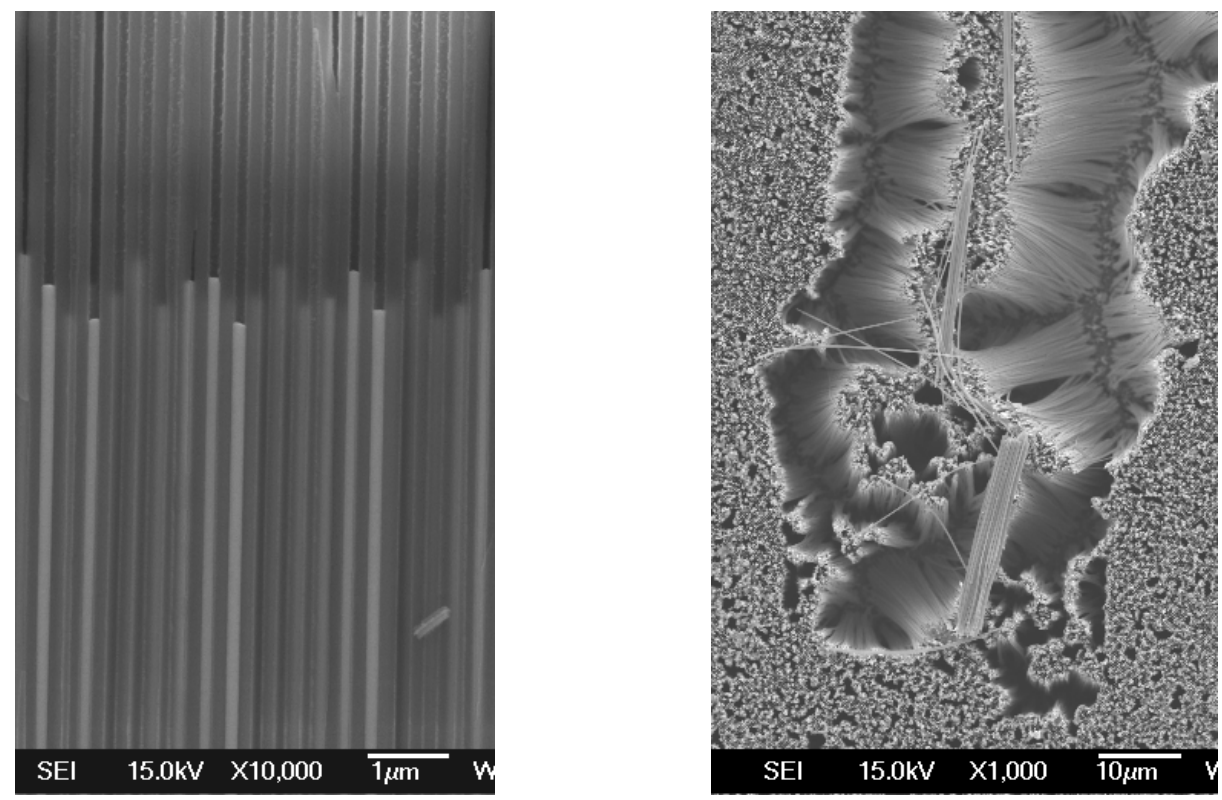

Fig. 27. Left: Nickel metal nanowires supported in their host alumina ceramic matrix, cross section view. Right: Plan view of free standing nickel metal nanowires whose PAA support matrix has been removed by etching. 


\subsection{Electrodeposition techniques for nanowire growth}

Planar templates 120 150 $\mu \mathrm{m}$ thick and $10 \mathrm{~mm}$ in diameter were fabricated in $0.3 \mathrm{M}$ oxalic acid (Brown et al., 2009). As described in section 2.2, the freestanding template was obtained by either dissolving the aluminium substrate in $1 \mathrm{M}$ iodine-methanol solution at $50{ }^{\circ} \mathrm{C}$ or by voltage pulse detachment in 1:1 perchloric acid / ethanol mix at room temperature (Yuan et al., 2006). The as-anodised template was chemically treated with $5 \mathrm{wt} \%$ phosphoric acid at $30{ }^{\circ} \mathrm{C}$ for 50 minutes, during which the barrier layer oxide was etched away leaving the template with open-ended pore channels. Electrodeposition was carried out under potentiostatic and galvanostatic conditions using a 3-electrode system. The process was driven by NOVA software provided by Eco Chemie, and the deposition time was controlled precisely to the nearest second. For the working electrode, a $50 \mathrm{~nm}$ thick conductive layer (Ag or $\mathrm{Au}$ ) was sputter-coated on one face of the template. $\mathrm{An} \mathrm{Ag} / \mathrm{AgCl}$ in $3 \mathrm{M} \mathrm{KCl}$ reference electrode was used, and the counter electrode was of the same material as the target species in the electroplating bath.

For nickel plating, an aqueous solution containing $300 \mathrm{~g} / \mathrm{L} \mathrm{NiSO}_{4} \cdot 6 \mathrm{H}_{2} \mathrm{O}, 45 \mathrm{~g} / \mathrm{L} \mathrm{H}_{3} \mathrm{BO}_{3}$, and $45 \mathrm{~g} / \mathrm{L} \mathrm{NiCl}_{2} .6 \mathrm{H}_{2} \mathrm{O}$ was used. The deposition was carried out at $-0.9 \mathrm{~V}$ potentiostatically at ambient temperature. For silver plating, the bath contained $17 \mathrm{~g} / \mathrm{L} \mathrm{AgNO}, 5.85 \mathrm{~g} / \mathrm{L} \mathrm{NaCl}$, and $39.5 \mathrm{~g} / \mathrm{L} \mathrm{Na}_{2} \mathrm{~S}_{2} \mathrm{O}_{3}$. The deposition was carried out at ambient temperature, galvanostatically at $2 \mathrm{~mA} \mathrm{/} \mathrm{cm}^{2}$. For copper plating, a solution containing $200 \mathrm{~g} / \mathrm{L}$ $\mathrm{CuSO}_{4} .5 \mathrm{H}_{2} \mathrm{O}$ and $25 \mathrm{~mL} / \mathrm{L}$ conc. $\mathrm{H}_{2} \mathrm{SO}_{4}$ was used at $-0.1 \mathrm{~V}$. The samples were rinsed in distilled water before and after deposition. $5 \mathrm{wt} \%$ phosphoric acid was used as the etching solution to remove the anodic alumina template.

\subsection{Fabrication of free standing nanowires}

Electrodeposition of conductive materials into PAA templates to form nanowire materials is a simple and versatile method. Fig. 28 demonstrates that under potentiostatic conditions, the deposition rate remained constant and the deposited nanowires had a linear increase in length after an extra 4 hours of deposition. Based on the total measured amount of charge transferred and the approximate total volume of these nickel nanowires, the electroplating process was $100 \%$ efficient when compared to the theoretical values.

Each template was kept wet prior to electrodeposition to ensure there were no trapped air bubbles to block the pore channels. The charge transferred over a specific deposition time can be used to calculate the theoretical volume of material reduced in a $100 \%$ efficient process, enabling control of the nanowire length. The alternative option is to closely monitor the current density (current per area) during deposition. Under potentiostatic conditions, any change in the surface area exposed to deposition will change the current density. After deposition and the removal of the template, the micrograph (Fig. 29) demonstrates how the ordered hexagonal array is translated from the PAA to the nanowires. In this case XRD analysis shows only the peak of the (220) plane for $\mathrm{Ni}$, indicating a preferred growth orientation in the [110] direction.

The concept of template-assisted fabrication of nanowires is further illustrated in Fig. 30 where the pore branching created by hierarchical fabrication techniques (section 2.3) is mirrored by the branched pore structure developed in the metal nanowires, in this case copper nanowires. Provided there is clear passage for the plating solution, it is simple 
process to design hierarchical nanowire structures using an anodic alumina template (Wu et al, 2010a).

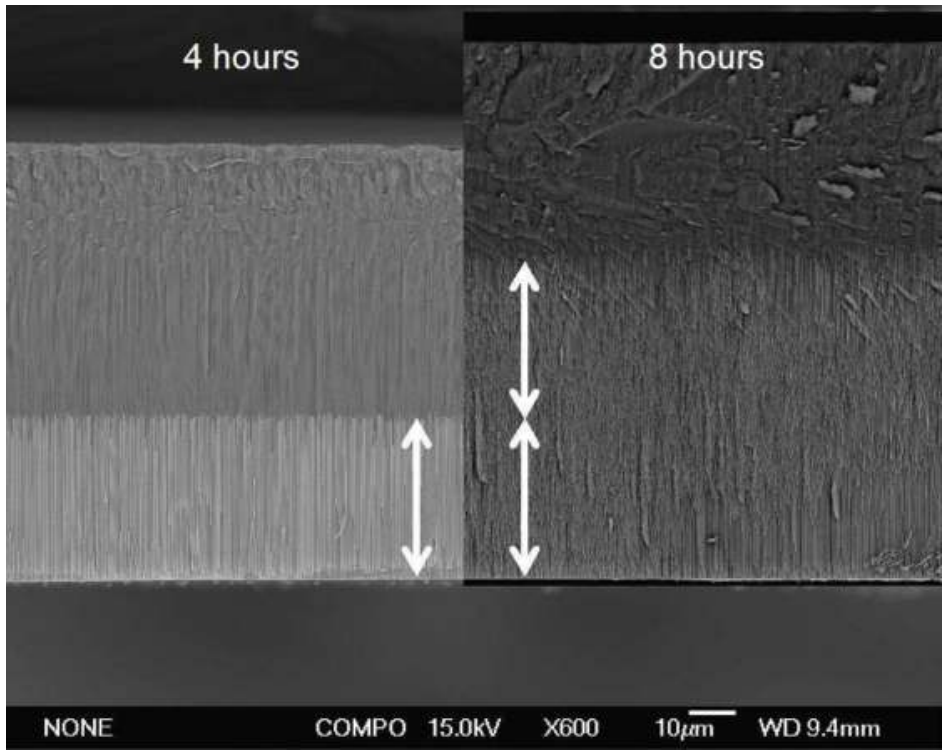

Fig. 28. Electrodeposited nickel in nano-channels of anodic alumina templates after 4 and 8 hours.

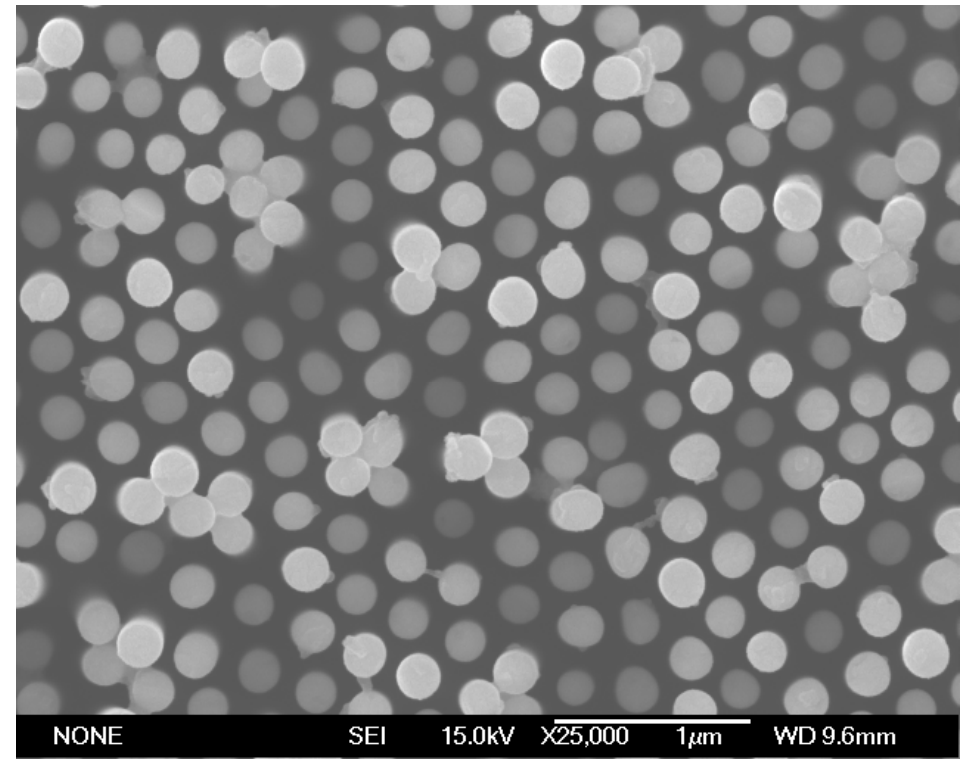

Fig. 29. Plan view of freestanding nickel nanowires $(25 \mu \mathrm{m}$ long, $\sim 100 \mathrm{~nm}$ in diameter) after removal of PAA. 


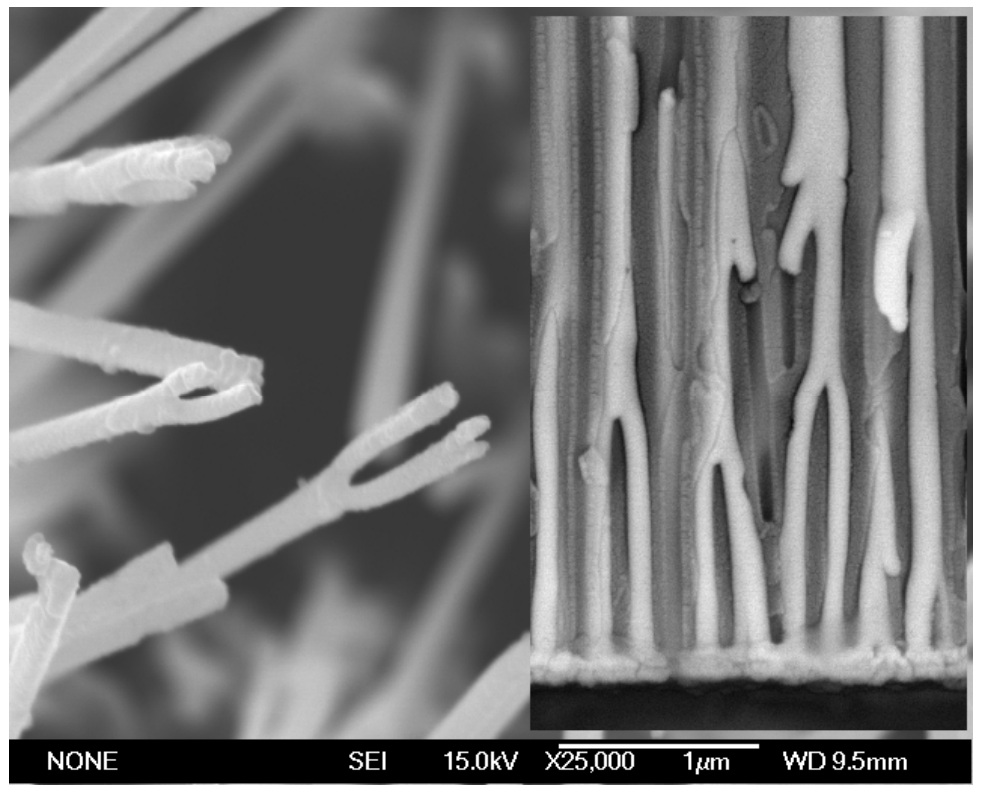

Fig. 30. Branched copper nanowires. Inset: branched nano-channels of an etched anodic alumina template, showing copper deposits formed in situ.

Segmented nanowires containing a combination of nickel, copper and silver have also been successfully prepared (Wu et al., 2010a) (Fig. 31). The backscattered electron image shows the contrast created by the atomic mass difference between the metals. However, on close examination, the silver deposition appeared to be the most problematic, providing poor coherence and less dense deposition. This was caused by the relatively high current density used during deposition when compared to nickel and copper, indicating that milder electrodeposition conditions are required for electroplating of silver species in these mixed metal systems.

Considerable research is active internationally in metal nanowire growth in PAA templates (Choi et al., 2003; Lombardi et al., 2006; Sander \& Tan, 2003) and is well summarised in a recent comprehensive review by Kartopu and Yalçın (2010). As well as metal deposition techniques, other species such as $\mathrm{ZnO}$ piezoelectric materials (Wang et al., 2005) and conductive polymers are currently being investigated to make nanowires and nanowire arrays for sensors, actuators, capacitors, and ultrasonic devices by utilising the high aspect ratio, high surface area, wave-guiding ability of these collinear structures (Harris et al., 2007). 


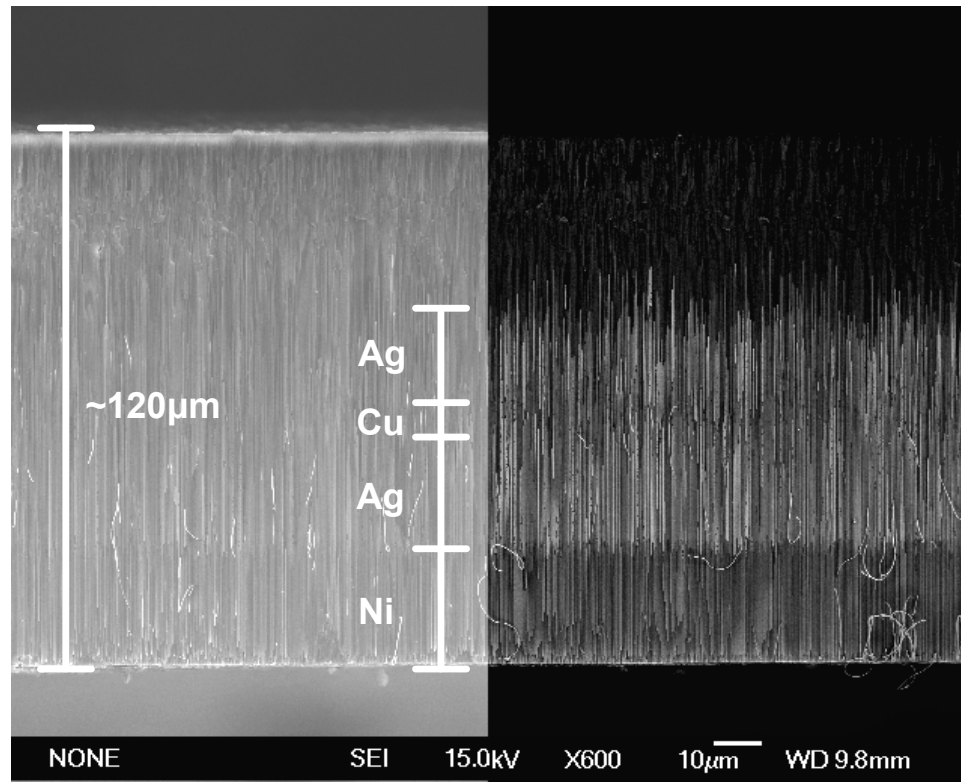

Fig. 31. Ni-Ag-Cu-Ag nanowires electroplated inside PAA membrane, $120 \mu \mathrm{m}$ thick.

\section{Conclusion}

Fabrication methodologies for porous anodic alumina (PAA) membranes using phosphoric, sulphuric and oxalic acid electrolytes have been presented. Mild anodisation (MA) techniques employ the minimum voltage conditions compatible with oxide growth with a penalty of long membrane growth times, typically 12-24 h. Hard anodisation (HA) techniques commence with the deposition of an oxide barrier layer formed under MA conditions, prior to ramping up the anodising voltage to the highest sustainable voltage compatible with a stable oxide growth regime and with heat dissipation in the anodisation rig. The growth rates achieved using HA conditions may be up to $100 \mathrm{~nm} \cdot \mathrm{h}^{-1}$. Both MA and HA membranes may be detached from their host metal substrates by dissolution of the $\mathrm{Al}$ metal in Iodine-EtOH solutions (slow) or by application of a brief high voltage pulse, typically 10-20 V higher than the maximum anodisation voltage (fast). The high voltage pulse punctures the closed basal pore caps and the acid environment causes immediate detachment of the membrane from the Al metal. The penalty for HA use is the greatly increased resistance of the ceramic to conventional acidic pore opening treatments, necessitating careful process design to establish MA type (etchable) zones at the basal face of the membrane.

Irrespective of the acid electrolyte used during their formation all PAA structures are X-ray amorphous. Examination of the structural and thermal properties of these membranes shows that they display unique short range ordering, having a mix of 4,5 and 6 coordinated $\mathrm{Al}^{3+}$, with the approximate proportions $\mathrm{AlO}_{4} 14 \%, \mathrm{AlO}_{5} 57 \%$ and $\mathrm{AlO}_{6} 29 \%$, respectively. This structure is stable until $>700{ }^{\circ} \mathrm{C}$ at which point a series of thermal events occurs whose 
detailed outcome is strongly directly by ionic species $\left(\mathrm{PO}_{4}^{3-}, \mathrm{CO}_{3}{ }^{2}, \mathrm{SO}_{4}{ }^{2-}\right)$ incorporated into the alumina matrix from the acid electrolyte. A combination of ${ }^{27} \mathrm{Al}$ SS NMR, XRD, MS and Thermal Analysis enables knowledge of a complete picture of the structure and thermal transformations of these membranes from totally amorphous through intermediate transitional alumina structures to a fully crystallized $\mathrm{a}-\mathrm{Al}_{2} \mathrm{O}_{3}$ membrane above $1200{ }^{\circ} \mathrm{C}$.

Knowledge of these structural changes in response to thermal treatment is an important condition for use of these materials in high temperature applications. In this context the use of PAA membranes as templates for the formation of palladium-based ultra-thin film hydrogen gas separation devices has been described. Finally, a brief introduction is given to the use of PAA host structures for the fabrication of metal nanowires, a technique with the potential to be a key methodology for future electronic device development.

\section{Acknowledgments}

The authors gratefully acknowledge the key contributions of principal researchers Mark Bowden, Alexander Kirchner, Ken MacKenzie and Tim Kemmitt and the valued contributions of numerous student researchers, including Elly Jay, Melanie Nelson, Naser Al-Mufachi and Jules Carvalho. This research has been supported by the New Zealand Ministry of Science and Innovation and the MacDiarmid Institute for Advanced Materials and Nanotechnology.

\section{References}

Asoh, H., Nishio, K., Nakao, M., Tamamura, T. \& Masuda, H. (2001). Conditions for fabrication of ideally ordered anodic porous alumina using pretextured $\mathrm{Al}, \mathrm{J}$. Electrochem. Soc. Vol. 148, B152-156.

de Azevedo, W.M., de Carvalho, D.D., de Vasconcelos, E.A. \& da Silva Jr., E.F. (2004). Photoluminescence characteristics of rare earth-doped nanoporous aluminium oxide, Appl. Surf. Sci. Vol. 234, p.457-461.

Baschuk, J.J. \& Li, X. (2003). Modelling CO Poisoning and $\mathrm{O}_{2}$ Bleeding in a PEM Fuel Cell Anode, Int. J. Energy Res. Vol.27, pp1095-1116.

Bhat, V.V., Contescu, C.I. \& Gallego, N.C. (2009). The role of destabilization of palladium hydride in the hydrogen uptake of Pd-containing activated carbons, Nanotechnology Vol. 20, pp.204011-20 (doi:10.1088/0957-4484/20/20/204011).

Brown, I.W.M., Bowden, M.E., Kemmitt, T. \& MacKenzie, K.J.D (2006). Structural and Thermal Characterisation of Nanostructured Alumina Templates Current Applied Physics Vol. 6 (3), pp.557-561.

Brown, I.W.M., Bowden, M.E., Kemmitt, T., Kirchner, A. \& MacKenzie, K.J.D. (2007). New Ceramic Membrane Materials for Gas Purification. Advanced Materials Research Vol. 29-30, pp.15-20.

Brown, I.W.M., Bowden, M.E., Jay, E., Kemmitt, T., Kirchner, A., MacKenzie K.J.D. \& Smith, G., (2008). Nanostructured Alumina Ceramic Membranes for Hydrogen Separation, in Global Roadmap for Ceramics - Proceedings of ICC2, (ISTEC-CNR, 
Institute of Science and Technology for Ceramics - National Research Council, pp.319-328.

Brown, I., Bowden, M., Kemmitt, T., Wu, J \& Carvalho, J.(2009) Nanostructured Alumina Ceramic Membranes for Gas Separation. International Journal of Modern Physics B. Vol. 23, Nos. 6 \& 7. pp.1015-1020.

Brown, I., Wu, J., Nelson, M., Bowden, M. \& Kemmitt, T. (2010) Hydrogen Separation Membranes from Nanostructured Alumina Ceramics Pp 1-16 in "Nanostructured Materials and Systems": Ceramic Transactions of the American Ceramic Society, Volume 214, Eds Sanjay Mathur \& Hao Shen, ISBN: 978-0-470-88128-6, 168 pages, July 2010.

Chase, M. (1998). NIST-JANAF Thermochemical Tables, 4th ed., J. Phys. Chem. Ref. Data, Monograph 9.

Chen, W., Wu, J.S., Yuan, J.H., Xia, X.H. \& Lin, X.H. (2007). An environment-friendly electrochemical detachment method for porous anodic alumina, Journal of Electroanalytical Chemistry, Vol 600, pp.257-264.

Cheng, Y.S. \& Yeung, K.L. (1999). Palladium-silver composite membranes by electroless plating technique. Journal of Membrane Science Vol.158, pp.127-141.

Cho, S.H., Walther, N.D., Nguyen, S.T. \& Hupp, J.T. (2005). Anodic aluminium oxide catalytic membranes for asymmetric epoxidation, Chem. Commun. pp.5331-3.

Choi, J., Sauer, G., Nielsch, K., Wehrspohn, R.B. \& Gösele, U. (2003). Hexagonally arranged monodisperse silver nanowires with adjustable diameter and high aspect ratio, Chem. Mater. Vol.15, pp.776-779.

Collins, J.P. \& Way, J.D. (1993). Preparation and Characterization of Palladium-Ceramic Composite Membranes, Ind. Eng. Chem., Vol.32, pp.3006-13.

Farnan, I., Dupree, R., Forty, A.J., Jeong, Y.S., Thompson, G.E. \& Wood, G.C. (1989). Structural information about amorphous anodic alumina from 27Al MAS NMR, Philos. Mag. Lett. Vol.59, pp189-195.

Flanagan T.B. \& Sakamoto, Y. (1993). Hydrogen in Disordered and Ordered Palladium Alloys, Platinum Metals Rev., Vol.37(1), pp.26-37.

Furneaux, R.C., Rigby, W.R. \& Davidson, A.P. (1989). The formation of controlled porosity membranes from anodically oxidized aluminium, Nature Vol.337 pp.147-149.

Goods, S.H. \& Guthrie, S.E. (1992). Mechanical properties of palladium and palladium hydride, Scripta Metallurgica Vol.26(4), pp. 561-566.

Harris, P., Dawson, A., Young, R. \& Lecarpentier, F. (2007). High frequency propagation in structured solids, in Proc. 2007 IEEE International Ultrasonics Symposium, New York, pp. 690-693.

Iijima, T., Kato, S., Ikeda, R., Ohki, S., Kido, G., Tansho, M. \& Shimizu, T. (2005). Structure of duplex oxide layer in porous alumina studied by 27Al MAS and MQMAS NMR, Chem. Lett. Vol.34, pp1286-1287.

Kartopu, G. \& Yalçın, O. (2010). Fabrication and Applications of Metal Nanowire Arrays Electrodeposited in Ordered Porous Templates. pp 113-140 in Electrodeposited Nanowires and Their Applications, Book edited by: Nicoleta Lupu. ISBN 978-9537619-88-6, pp. 228, February 2010, INTECH, Croatia. 
Kikuchi, E. \& Uemiya, S. (1991). Preparation of supported thin palladium-silver alloy membranes and their characteristics for hydrogen separation, Gas Separation $\mathcal{E}$ Purification, Vol.5, pp.261-266.

Kirchner, A., MacKenzie, K.J.D., Brown, I.W.M., Kemmitt, T. \& Bowden, M.E. (2007a). Structural characterisation of heat-treated anodic alumina membranes prepared using a simplified fabrication process, Journal of Membrane Science Vol. 287(2), pp.264-270.

Kirchner, A., Brown, I.W.M., Bowden, M.E., \& Kemmitt, T. (2007b). Hydrogen Purification using Ultra-thin Palladium Films supported on Porous Anodic Alumina Membranes, in Functional Nanoscale Ceramics for Energy Systems, ed. E. Ivers-Tiffee and S. Barnett (Mater. Res. Soc. Symp. Proc. 1023E, Warrendale, PA, 2007), Paper 1023-JJ09-02.

Kirchner, A., Brown, I.W.M., Bowden, M.E., Kemmitt, T. \& Smith, G. (2008). Preparation and high-temperature characterisation of nanostructured alumina ceramic membranes for high value gas purification, Current Applied Physics Vol. 8, pp.451454.

Lee, W., Ji, R., Ross, C.A., Gösele, U., \&. Nielsch, K. (2006a). Wafer-scale Ni imprint stamps for porous alumina membranes based on interference lithography. Small, Vol. 2, pp.978-982.

Lee, W., Ji, R., Gösele, U. \& Nielsch, K. (2006b). Fast fabrication of long-range ordered porous alumina membranes by hard anodization. Nature Materials Vol. 5 (9) , pp 741-747.

Li, A.P., Müller, F., Birner, A. \& Gösele, U. (1998). Hexagonal pore arrays with a 50-420 nm interpore distance formed by self-organization in anodic alumina, J. Appl. Phys. Vol. 84, pp.6023-6026.

Lira, H. de L. \& Paterson, R. (2002). New and modified anodic alumina membranes. Part III. Preparation and characterisation by gas diffusion of $5 \mathrm{~nm}$ pore size anodic alumina membranes, J. Membrane Sci., Vol. 206, pp.375-387.

Lombardi, I., Magagnin, L., Cavalotti, P.L., Carraro, C. \& Maboudian, R. (2006). Electrochemical fabrication of supported $\mathrm{Ni}$ nanostructures through transferred porous anodic alumina mask, Electrochem. Solid State Lett. Vol. 9, pp.D13-D16.

MacKenzie, K.J.D. \& Smith, M.E. (2002). Multinuclear Solid-State NMR of Inorganic Materials, Pergamon, Amsterdam. ISBN 0-08-043787-7.

Mardilovich, P.P., Govyadinov, A.N., Mukhurov, N.I., Rzhevskii, A.M. \& Paterson, R. (1995). New and modified anodic alumina membranes. Part I. Thermotreatment of anodic alumina membranes, J. Mem. Sci. Vol .98, pp.131-142.

Mardilovich, P.P., She, Y. \& Ma, Y.H. (1998). Defect-free palladium membranes on porous stainless steel support, AIChE Journal, Vol.44(2), pp.310-322.

Masuda, H., \& Fukuda, K. (1995) Ordered metal nanohole arrays made by a two-step replication of honeycomb structures of anodic alumina, Science Vol. 268, pp.14661468.

Masuda, H., Hasegawa, F. \& Ono, S. (1997). Self-ordering of cell arrangement of anodic porous alumina formed in sulphuric acid solution, J. Electrochem. Soc. Vol. 144, pp.L127-L129. 
Masuda, H., Yada, K., \& Osaka, A. (1998). Self-ordering of cell configuration of anodic porous alumina with large-size pores in phosphoric acid solutions, Jpn. J.Appl. Phys. Vol. 37, pp.L1340-L1342.

Masuda, H., Ohya, M., Nishio, K., Asoh, H., Nakao, M., Nohtomi, M., Yokoo, A. and Tamamura, T. (2000). Photonic band gap in anodic porous alumina with extremely high aspect ratio formed in phosphoric acid solution, Jpn. J.Appl. Phys. Vol.39, pp.L1039-L1041.

Müller, D., Gessner, W., Samosan, A., Lippmaa, E. \& Scheler, G. (1986). J.Chem. Soc. Dalton Trans. Vol.1986, pp1277-1281.

Müller, D., Jahn, E., Ladwig, G. \& Haubenreisser, U. (1984). Chem. Phys. Lett. Vol.109, pp.332-336.

O'Sullivan, J.P. \& Wood, G.C. (1970). The morphology and mechanism of formation of porous anodic films on aluminium, Proc. Roy. Soc. London A Vol. 317 pp.511-543.

Ozao, R., Ochiai, M., Yoshida, H., Ichimura, Y. \& Inada, T. (2001). Preparation of gamma alumina membranes from sulphuric electrolyte anodic alumina and its transition to alpha alumina, J. Thermal Anal. Calorim. Vol. 64, pp.923-932.

Paglieri, S.N. (2006). Palladium Membranes, in Nonporous Inorganic Membranes. Published Online: 3 Aug 2006, Eds. A.F. Sammells, M.V. Mundschau, Print ISBN: 9783527313426, Online ISBN: 9783527608799, pp77-105.

Robinson, A.P, Burnell, G., Hu, M. \& MacManus-Driscoll, J.L. (2007). Controlled, perfect ordering in ultrathin anodic aluminum oxide templates on silicon. Applied Physics Letters Vol.91, pp.143123(3).

Roy, S., Raju, R., Chuang, H.F., Cruden, B.A. \& and Meyyappan, M. (2003). Modeling gas flow through microchannels and nanopores, in J. Appl. Phys., Vol. 93, pp.48704879 .

Sander, M.S. \& Tan, L.S. (2003). Nanoparticle arrays on surfaces fabricated using anodic alumina films as templates, Adv. Funct. Mater. Vol.13, pp.393-397.

Sano, T., Iguchi, N., Iida, K., Sakamoto, T., Baba, M. \& Kawaura, H. (2003). Size-exclusion chromatography using self-organized nanopores in anodic porous alumina, Appl. Phys. Lett. Vol. 83, pp.4438-4440.

Sulka, G.D., (2008) Highly Ordered Anodic Porous Alumina Formation by Self-Organising Anodising. Chapter 1 in Nanostructured Materials in Electrochemistry, Ed A. Eftekhari, Publ. Wiley-VCH Verlag GmbH \& Co., Weinhein, Germany. (2008). ISBN: 978-3-527-31876-6.

Thompson, G.E. (1997). Porous anodic alumina: fabrication, characterization and applications, Thin Solid Films, Vol. 297, pp.192-201.

Uemiya, S., Matsuda, T. \& Kikuchi, E. (1991). Hydrogen permeable palladium-silver alloy membrane supported on porous ceramics, Journal of Membrane Science, Vol.56, pp.315-325.

Uribe, F.A., Valerio, J.A., Garzon, F.H. \& Zawodzinski, T.A. (2004). PEMFC Reconfigured Anodes for Enhancing CO Tolerance with Air Bleed, Electrochem. Solid-State Lett. Vol.7, pp.A376-A379.

Wang, Q., Wang, G., Xu, B., Jie, J., Han, X., Li, G., Li, Q. \& Hou, J.G. (2005). Non-aqueous cathodic electrodeposition of large-scale uniform $\mathrm{ZnO}$ nanowire arrays 
embedded in anodic alumina membrane. Materials Letters, Vol. 59 (11) pp.13781382.

Wang, Y.C., Leu, I.C. \& Hon, M.H. (2004). Dielectric property and structure of anodic alumina template and their effects on the electrophoretic deposition characteristics of $\mathrm{ZnO}$ nanowire arrays, J. Appl. Phys. Vol. 95, pp1444-1449.

Wu, Jeremy P., Brown, Ian W.M., Kemmitt, Tim, \& Bowden, Mark E. (2010a) Hierarchical Anodic Alumina Template-assisted Fabrication of Nanowires. Proc. of International Conference on Nanoscience and Nanotechnology (ICONN), 2010. Page(s): 29 - 32 DOI: 10.1109/ICONN.2010.6045163. Publ. IEEE Xplore.

Wu, Jeremy. P., Brown, Ian W.M., Bowden, Mark E. \& Kemmitt, Timothy (2010b). Palladium coated porous anodic alumina membranes for gas reforming processes. Solid State Sciences Vol 12 pp1912-1916.

Yuan, J.H., Chen, W., Hui, R.J., Hu Y.L. \& Xia, X.H. (2006). Mechanism of one-step voltage pulse detachment of porous anodic alumina membranes, Electrochimica Acta, Vol. 51, pp.4589-4595. 


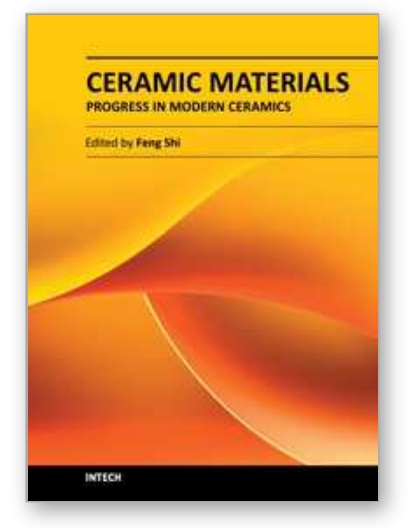

\author{
Ceramic Materials - Progress in Modern Ceramics \\ Edited by Prof. Feng Shi
}

ISBN 978-953-51-0476-6

Hard cover, 228 pages

Publisher InTech

Published online 05, April, 2012

Published in print edition April, 2012

This text covers ceramic materials from the fundamentals to industrial applications. This includes their impact on the modern technologies, including nano-ceramic, ceramic matrix composites, nanostructured ceramic membranes, porous ceramics, and the sintering theory model of modern ceramics.

\title{
How to reference
}

In order to correctly reference this scholarly work, feel free to copy and paste the following:

Ian W. M. Brown, Jeremy P. Wu and Geoff Smith (2012). Fabrication, Structure and Properties of Nanostructured Ceramic Membranes, Ceramic Materials - Progress in Modern Ceramics, Prof. Feng Shi (Ed.), ISBN: 978-953-51-0476-6, InTech, Available from: http://www.intechopen.com/books/ceramic-materialsprogress-in-modern-ceramics/fabrication-structure-and-properties-of-nanostructured-ceramic-membranes

\section{INTECH}

open science | open minds

\section{InTech Europe}

University Campus STeP Ri

Slavka Krautzeka 83/A

51000 Rijeka, Croatia

Phone: +385 (51) 770447

Fax: +385 (51) 686166

www.intechopen.com

\section{InTech China}

Unit 405, Office Block, Hotel Equatorial Shanghai

No.65, Yan An Road (West), Shanghai, 200040, China 中国上海市延安西路65号上海国际贵都大饭店办公楼 405 单元

Phone: +86-21-62489820

Fax: $+86-21-62489821$ 
(C) 2012 The Author(s). Licensee IntechOpen. This is an open access article distributed under the terms of the Creative Commons Attribution 3.0 License, which permits unrestricted use, distribution, and reproduction in any medium, provided the original work is properly cited. 